\title{
Spatial connectivity as a recovery process indicator: The L'Aquila earthquake
}

\author{
Diana Contreras ${ }^{\mathrm{a}, *}$, Thomas Blaschke $^{\mathrm{b}, \mathrm{c}}$, Stefan Kienberger ${ }^{\mathrm{b}}$, Peter Zeil ${ }^{\mathrm{b}}$ \\ a Department of Geoinformatics, University of Salzburg, Austria, Salzburg \\ ${ }^{\mathrm{b}}$ Centre for Geoinformatics Z_GIS, University of Salzburg, Austria, Salzburg \\ c Research Studio iSPACE, Austria, Salzburg
}

\section{A R T I C L E I N F O}

\section{Article history:}

Received 2 December 2011

Received in revised form 12 November 2012

Accepted 7 December 2012

Available online $\mathrm{xxxx}$

\section{Keywords:}

Vulnerability

Earthquakes

Recovery

Indicators

Spatial connectivity

GIS

\begin{abstract}
A B S T R A C T
The main objective of this paper is to prove that spatial connectivity can be an effective spatial indicator for monitoring and evaluating the recovery process after the event of an earthquake. It integrates variables such as distance, travel time and quality of public transport service. We hypothesize that there is a relationship between the connectivity to the central business districts in cities, and the satisfaction with the locations of new settlements assigned to the homeless population during a recovery process. If this hypothesis holds true, then the satisfaction with new settlements will be correlated with the inhabitants' preference to either stay, or to search for a new site. This will then support the evaluation of the success of a recovery process. To prove this relationship we investigated the twelve months recovery process in L'Aquila in Italy. Spatial data sets were used and analyzed using GIS. Fieldwork data and interviews were conducted in order to investigate the satisfaction of persons living in newly established places outside of the city. We compared the strength of the desire of the interviewees to move away, against the travel distance and travel time to the city center. The statistical analysis reveals that the preference to search for another place was significantly correlated with the distance between new settlements and the city center of L'Aquila. To a lesser degree it was correlated with the travel time. The regression indicated that the distance between the new settlements and the inner city strongly influences the preference to either stay or to move.
\end{abstract}

(c) 2012 Elsevier Inc. All rights reserved.

\section{Introduction}

Throughout history, many cities like Berlin, Moscow, Mexico City, Tokyo, Kobe, Hiroshima, and Nagasaki have been destroyed by natural phenomena or anthropogenic events; nevertheless, most of them have managed to rebuild and rebound. Only 42 cities in the world were 'permanently abandoned following destruction' [1]; these cities include e.g. Pompeii (Italy) after the year AD 79, and Armero (Colombia) after the eruption of the "Nevado del Ruiz" Volcano. At least since the 19 th century resilience seems to have increased and

\footnotetext{
* Corresponding author at: University of Salzburg, Hellbrunnerstraße 34, 5020 Salzburg, Austria.

E-mail addresses: contrerasdi@stud.sbg.ac.at (D. Contreras), thomas.blaschke@sbg.ac.at (T. Blaschke), stefan.kienberger@sbg.ac.at (S. Kienberger), peter.zeil@sbg.ac.at (P. Zeil).
}

the recovery of cities such as New Orleans after the impact of Hurricane Katrina is more likely.

On April 6th of 2009, an earthquake with a magnitude of $6.3 \mathrm{M}_{\mathrm{W}}$, at a depth of $10 \mathrm{~km}$ and at an epicenter located $34 \mathrm{~km}$ to the Southwest of the city of L'Aquila in Italy struck the city (population 728.000), the capital of the province by the same name, and a major center of the Abruzzo region. Its location and the map of ground motion intensity during the earthquake are displayed in Fig. 1.

The historical city was destroyed, 1.500 people were injured, 202 of them seriously, 308 lost their life, 67.500 became homeless [2], and between 3.000 and 10.000 buildings were damaged. The cost of the damage was estimated to be 16 billion Euros [3]. The classification of the degree of damage per block after the earthquake in L'Aquila is depicted in Fig. 2.

Reconstruction programs like the C.A.S.E (Complessi Antisismici Sostenibili ed Ecocompatibili) and M.A.P. (Moduli. Abitaviti Provvisori) helped to build about 284 housing units in 


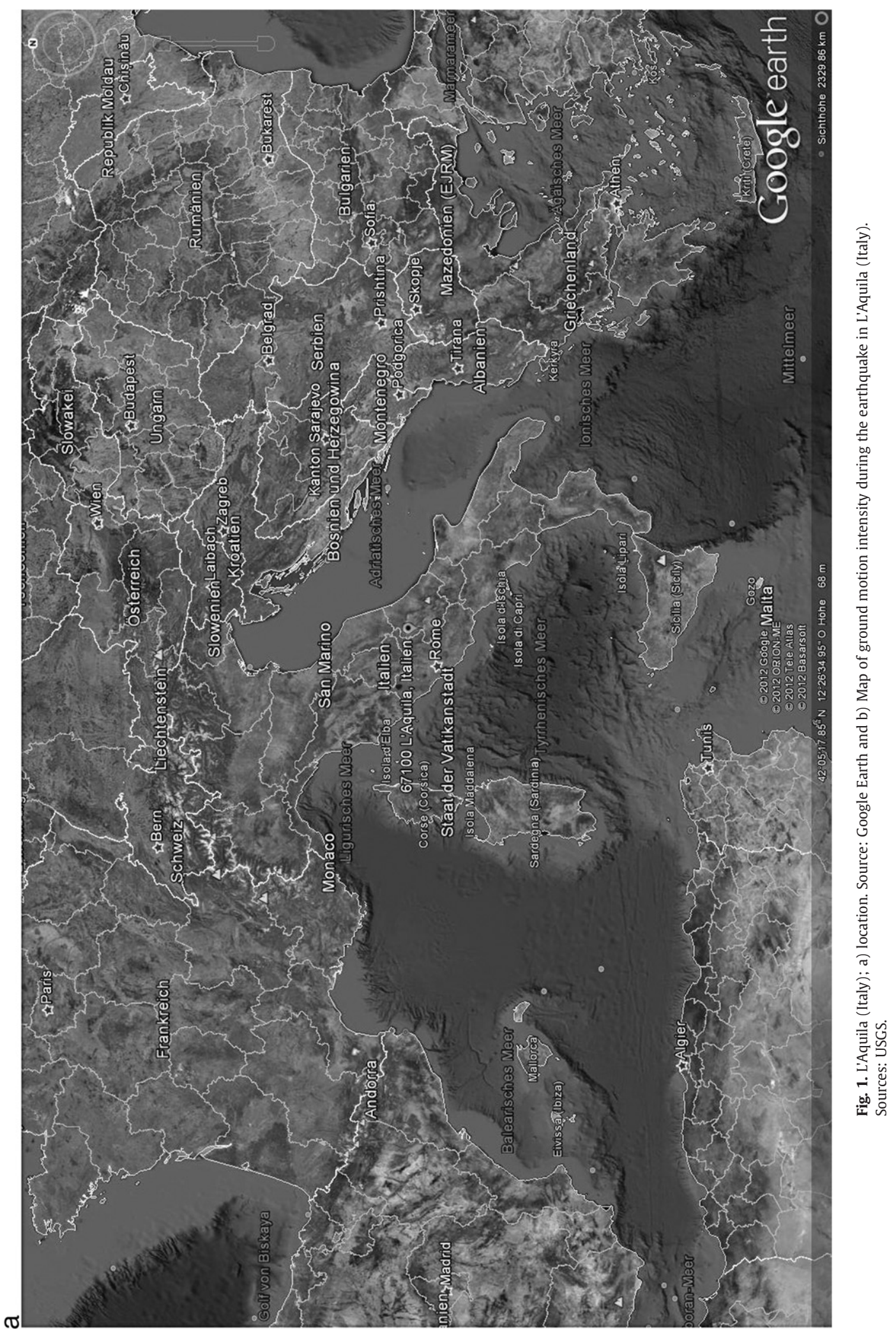




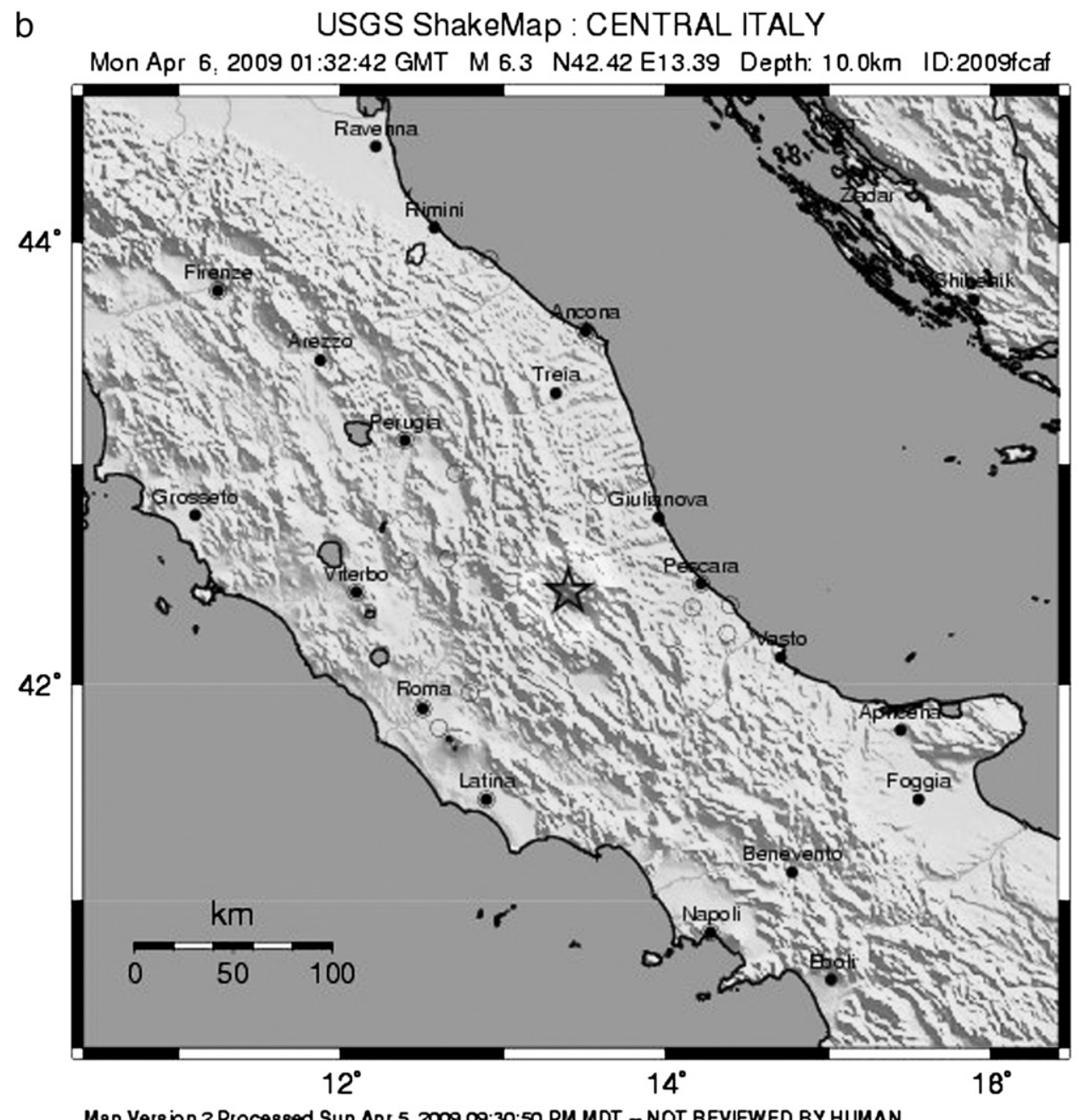

Map Version 2 Processed Sun Apr 5, 2009 09:30:50 PIM MDT - NOT REVIEWED BY HUIMAN

\begin{tabular}{|c|c|c|c|c|c|c|c|c|c|}
\hline $\begin{array}{l}\text { PEACENEED } \\
\text { SHAKIMG }\end{array}$ & Not felt & Weak & Light & Moderate & Strong & Very strong & Severe & Violent & Extreme \\
\hline $\begin{array}{l}\text { POTENTIIAL } \\
\text { DAMAGE }\end{array}$ & none & none & none & Very ight & Light & Moderate & Iroderate'Heavy & Heavy & Very Heavy \\
\hline PEAK ACC (li.g) & $<.17$ & $.17-1.4$ & $1.4-3.9$ & 3.99 .2 & $9.2-18$ & $18-34$ & $3+65$ & $65-124$ & $>124$ \\
\hline PEAK VEL_(cms) & $<0.1$ & $0.1-1.1$ & $1.1-3.4$ & $3.4-8.1$ & $8.1-16$ & $16-31$ & $31-60$ & $60-116$ & $>116$ \\
\hline $\begin{array}{l}\text { IIRSTRUMENTAL } \\
\text { IMTEMSIYY }\end{array}$ & I & IH-III & IV & V & VI & VII & VIII & DX & $x_{t}$ \\
\hline
\end{tabular}

Fig. 1 (continued).

19 new settlements in order to accommodate 23.000 survivors, who used to live in the city center. The locations of these new settlements are represented in Fig. 3. This quick and expensive housing solution, however, involves problems such as the lack of basic services, urban facilities (churches, schools, pharmacies, post offices, supermarkets, social centers, sport centers and so on), limited public transport (low and not reliable frequencies), social fragmentation and functional living, as well as questionable ecological values. Due to the dispersed and isolated location of these new settlements, initially designated as conservation land or farmland [4], people depend mainly on transport by private car to reach the area. The problem of being far away from the inner city not only means being far from services, but also from the scarce employment opportunities currently existing in L'Aquila. Next to the feeling, of some kind of forced migration, the location of the new settlements induces a dependency on private transport [4], which is neither cheap, nor environmentally friendly; as presented in Figs. 3 and 4.

UNDRO [5] identifies three strategies to address the problem of homeless people after a disaster: first, to continue living in the same house, because there is no damage (ideal solution); second, to provide temporary shelter, and later on provisional housing; and third, fast reconstruction of housing. L'Aquila adopted a combination of the second and third strategy. The second, according to UNDRO, is the most inefficient because it consists of 


\section{DEGREE OF DAMAGE AND ITS SPATIAL PATTERN \\ IN L'AQUILA (ITALY) AFTER THE EARTHQUAKE IN 2009}

Based on "Individuazione aree con fattibilita' a breve termine citta' di L'Aquila". Noi Abruzzo No. 1, March 23,2010

Adapted from Servizio per I'Informazione Territoriale e la Telematica - Ufficio Sistema Informativo Geografico - Regione Abruzzo

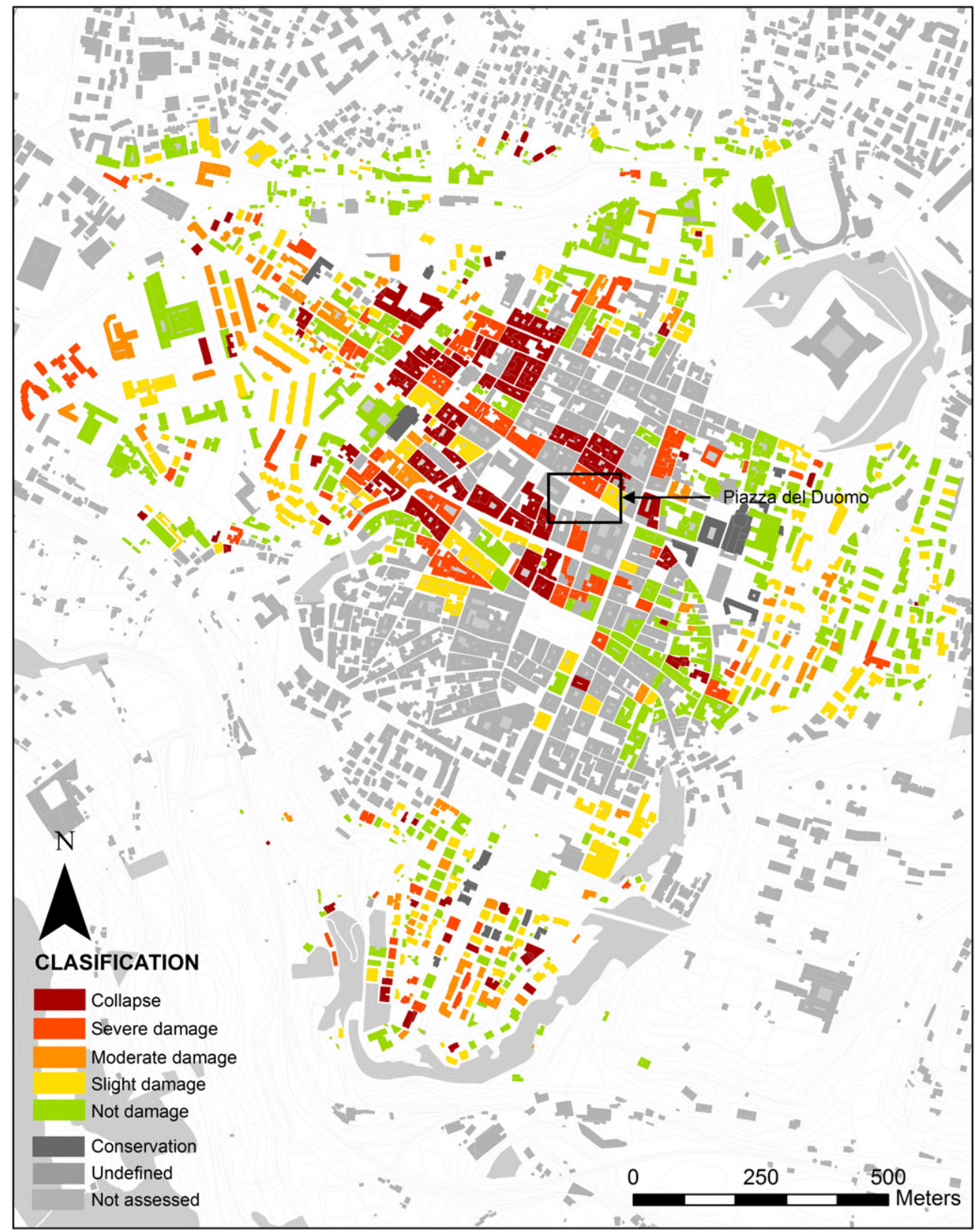

Fig. 2. Degree of damage and its spatial pattern in L'Aquila after the earthquake in 2009. Based on "Individuazione aree con fattibilita" a breve termine citta' di L'Aquila”. Noi Abruzzo No. 1, March 23, 2010. Servizio per l'informazione Territoriale e la Telematica - Ufficio Sistema Informativo Geografico - Regione Abruzzo.

two phases and it is expensive. Furthermore, the word "provisional" does not apply to housing, as it is the case with provisional housing developed in the United Kingdom during the First and Second World Wars, which is still used for housing. Also it has some characteristics of the third strategy, because there was a quick development of "provisional housing", but rather than talking about reconstruction, there was a kind of "forced migration" [4]. According to Clausen [6], more than 20.000 people in L'Aquila still live in temporary shelters, and the three billion dollar provisional housing solution seems to be permanent, while the city center is decaying behind the cordons and electro-soldier scaffold [7]. The construction of these provisional houses, in the case of the developed world, can take some months, while in developing countries it may take only several days, however, with a big difference in quality. The time required to provide housing to homeless people after an earthquake 
NEW SETTLEMENTS, INNER CITY AND OLD TOWN IN L'AQUILA - ITALY

Based on Senvizio per l'Informazione Territoriale e la Telematica - Ufficio Sistema Informativo Geografico - Regione Abruzzo. MICRODIS project - Commission's Sixth Framework Programme.

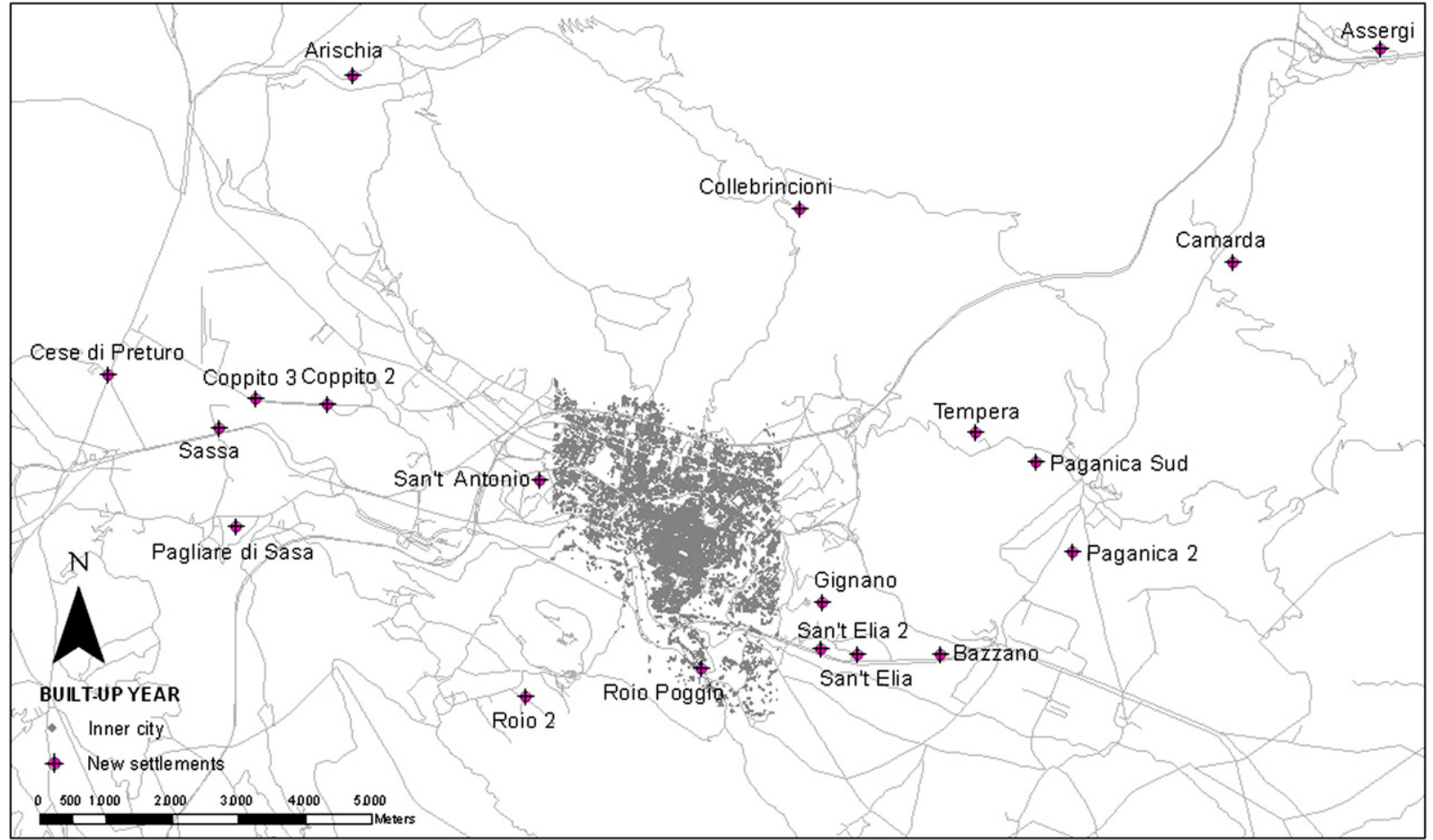

Fig. 3. Location of new settlements, inner city and old town in L'Aquila - Italy. Based on "Individuazione aree con fattibilita" a breve termine citta' di L'Aquila". Noi Abruzzo No. 1, March 23, 2010. Servizio per l'informazione Territoriale e la Telematica - Ufficio Sistema Informativo Geografico - Regione Abruzzo. MICRODIS Project - Commission's Sixth Framework Programme.

depends, among others, on the available funding and expertise, the commitment of the government, the housing culture, the level of participation with beneficiaries and the climatic conditions [5]. In the case of L'Aquila, neither funding nor expertise was a problem, in spite that there are a lot of questionable aspects such as the high costs and the use of wood as the building material of the houses. The weather wasn't a concern since the earthquake struck in spring, nevertheless there were some problems related with the high temperatures in summer, and localized floods during rainstorms [7]. Instead, there is a clear lack of commitment from the government and the level of participation of affected people was inexistent.

According to Alexander [4] the earthquake in L'Aquila "was a moderate seismic event". However, the high vulnerability level of its historic buildings - mainly concentrated in the city center led to the enormous damage described earlier. In the framework of the EC FP7 research project, Methods for the Improvement of Vulnerability Assessment in Europe (MOVE), vulnerability has been defined as "the susceptibility to suffer damages or the intrinsic fragility of the exposed elements, systems or communities that favors loss when affected by hazard events" [8]. Likewise, a clear concept of recovery is also essential. Nevertheless, the vulnerability of L'Aquila before the earthquake can not merely be reduced to the physical dimension in retrospective. The economic situation was characterized by stagnation due to the lack of improvement in the local infrastructure, the lack of employment opportunities, and devolution tax policies, which in the case of L'Aquila caused regressive effects; there is also a high vulnerability in the institutional dimension, taking into account that L'Aquila is poorly connected in political terms. Wisner et al. [9] state, more vulnerable areas will have longer recovery phases, and L'Aquila was a vulnerable area.

Several studies have demonstrated that disaster impacts - to different degrees - individuals and groups on accounts of the levels of vulnerability before the event [10]. Vulnerability assessment is a key contribution in order to formulate recovery and development policies during the risk management process.

Chang [11] puts forward three possible definitions for recovery: a) reaching the conditions existent before the event; b) reaching the state what would have been attained "without" the disaster, or c) reaching a new stable state. All these definitions are valid, and all of them reflect different cases and recovery processes, taking into account the preexistent vulnerability conditions. Recovery is a social process influenced by preand post-disaster conditions [10]. Vale \& Campanella [12] consider "city" as a place made up of buildings and infrastructure, with a significant density of residents, cultural and commercial facilities, social and political institutions, historic and symbolic meanings and social and spatial patterns [13]; and "recovery" the return to normalcy in the social and economic dimensions, even with the inequities existent before the event. Nevertheless, it is good to point out that a city consists of more than just buildings, resilience is more than physical reconstruction, and reconstruction is not necessarily recovery or vice versa [13]. 
a

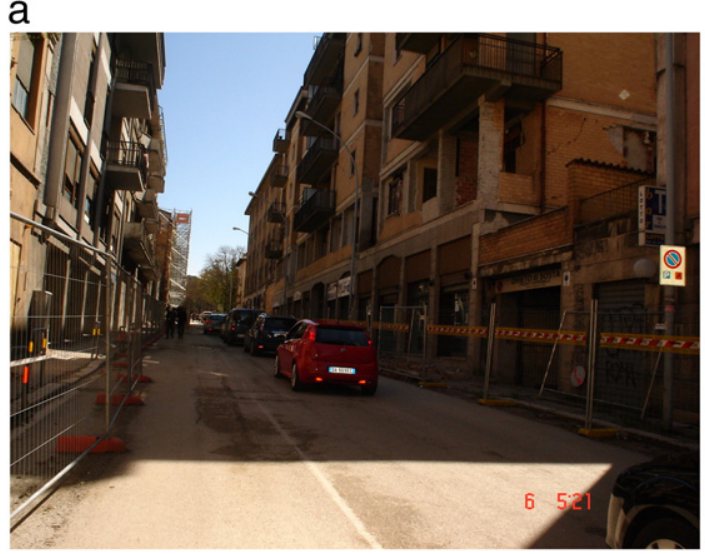

c

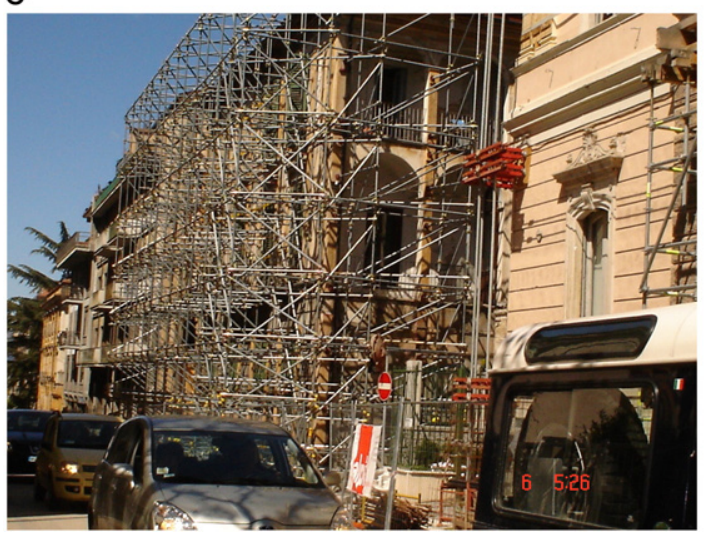

b

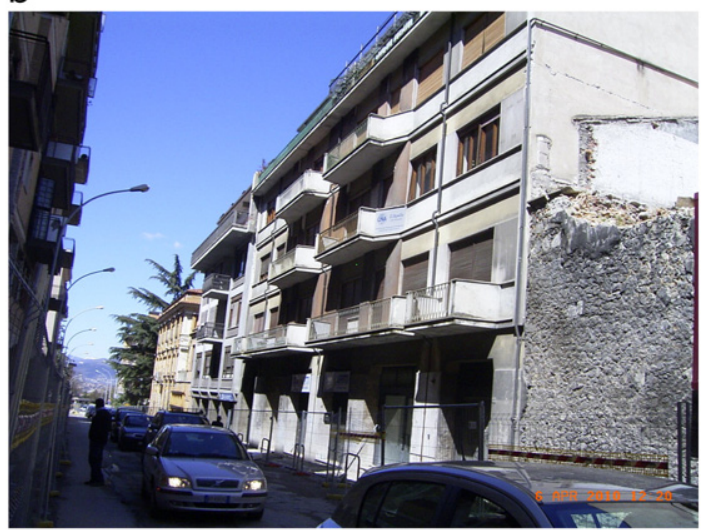

d

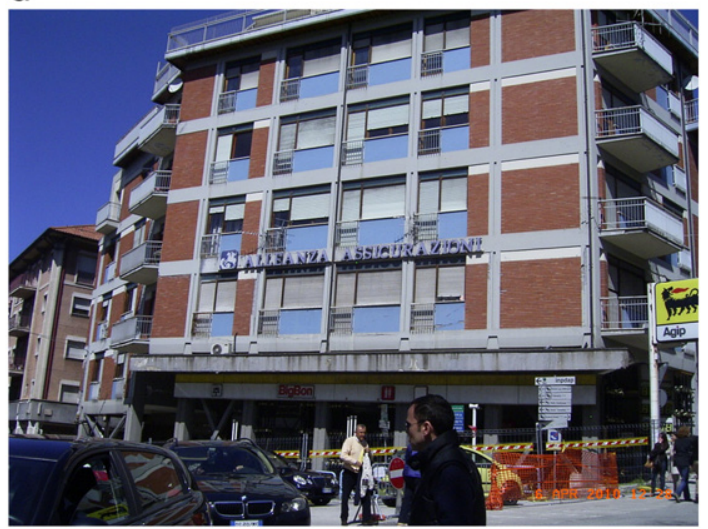

Fig. 4. Traffic jam on the way to the former central business district in L'Aquila (Via XX Settembre). (Diana M. Contreras M.).

In the concept of the present paper, recovery is defined as a complex multidimensional process of decision making after a disaster, strongly influenced by vulnerable conditions existing before the event, which address the interaction among a variety of groups and institutions, with the aim to rebuild people's lives and livelihoods, besides reconstructing buildings and infrastructure, restoring cultural assets and ecological conditions. This process offers the opportunity to improve pre-disaster conditions, avoid (re-) emerging vulnerabilities, and through the adaptation to the changed circumstances it may increase the community's disaster resilience. In spite that this uncertain and conflict-laden process is nonlinear and it does not have a clear boundary, it is divided into four phases: emergency, restoration/rehabilitation, recovery and redevelopment. Each phase has different objectives and activities in space and time, and the limits between them are fuzzy due to the unique characteristics of each area affected by a disaster.

The assessment of the recovery process should be based on indicators in order to guarantee objectivity and comparability [14]. Indicators are qualitative or quantitative measures resulting from systematically observed facts [15] which describe the characteristics and allow the assessment of certain phenomena [16]. Based on an extensive literature study which is reflected in the guidelines for up- and downscaling of indicators in the MOVE project, we decided to base our quest for spatial indicators preferably on measurable and mappable spatial variables such as area, range, distance, direction, spatial geometries and patterns, spatial connectivity, isolation, diffusion, spatial associations, and scale of the affected area and surroundings [17]. Measuring the spatial component of recovery is important, since both the disastrous event as well as the recovery process to follow, take place an explicit spatial context. Spatial indicators are visible measures of the stage, at which the recovery process is progressing, making it easier to design a recovery plan at earlier stages, and to evaluate it in a participatory way later.

Comparing the human body and the structure of a city, the central district in L'Aquila is the social, financial, institutional and cultural heart of the city; if the heart is not active, it is not possible to talk about recovery in the city, even if other parts or new parts in the city are active. As in the case of the human body, if the heart is not pumping blood through the vessels, there is no oxygen for the other organs in the body and it will soon die. In the case of the city, if the central district, which is also the central business district, is not functioning, then less customers, tourism, business and investment will come to the city, which also affects the new areas; and later on, the recovery feasibility or even the feasibility of the city to revitalize.

Cutter [18] has already highlighted the role of spatial analysis in all phases of the emergency response, specifically in activities such as threat detection, monitoring land use, design of potential evacuation routes or re-delineating hazard zones. In the recovery phase, GIScience allows for the dynamic 
representation of physical and social processes, which are the integral aspect for developing spatial indicators highlighting the progress of the recovery process. GIS combined with satellite images allows us to construct indicators of housing, reconstruction and land use change in the physical dimension, and generate proxy indicators of the social dimension, in order to measure the progress of the recovery.

Several indices have been developed to measure vulnerability, but only Yuka Karatani \& Hayashi [19,20]; Shohei [14] and Chang [11] yielded a recovery index. Since large-scale disasters are relatively rare it is difficult to accumulate the information and the experience 'across disasters' in order to create a more generic model to evaluate recovery processes [19]. One of the major events of the 20th and 21st century that has been carefully studied and documented, is the Kobe earthquake, but the status quo of establishing benchmarks is not satisfying. To our knowledge there are no defined protocols or benchmarks for recovery phases and it is repeatedly argued that every recovery phase is a unique combination of various external forces and disaster prevention policies applied in the area. Furthermore the recovery phase is determined by the unique history of the area [19]. In the case of disaster management, history means the vulnerability condition existing before the disaster, in this case an earthquake; and spatial connectivity can not be only a recovery, but also a vulnerability indicator. One of the aspects considered in the research study about the functional vulnerability in Bogotá D.C. (Colombia) in case of a disaster [21] is the spatial connectivity for the emergency response, identifying the probable roads blocked and collapsed bridges according to different damage scenarios, based on the return periods and hour of occurrence of the earthquake. Having the scenarios, the study identified the road with the least probability of being blocked, in order to be used by emergency response institutions, the unwounded, as well as for the transport of injured and deceased people. Other authors such as Ozdamar [22], Chiu [23], Fiedrich [24], and Yan [25] have also addressed the topic of transport, logistics and connectivity during the emergency phase, which are also elements related to connectivity, but not considered in the present research.

\section{Hypothesis and objectives}

Tierney [10] argues that one of the problems during the recovery phase in New Orleans after Hurricane Katrina was not only the return of the local population, but also the return of business, because individual businesses depend on local business ecologies or the interaction between organizations and individuals in the business world. Furthermore the recovery process requires sources of income and work [4], which is nowadays the problem that L'Aquila faces city due to the lack of both of them. In this sense, the hypothesis to be tested in this paper is that the changes in spatial pattern such as connectivity, change of land use, occupation, reactivation of areas and attachment to the new settlements can be used as spatial indicators for monitoring the success of a recovery process. In particular, the aim is to investigate the spatial connectivity between the new settlements built, and the inner city of L'Aquila. We hypothesize that if the connectivity decreases, the satisfaction with the location of new settlements also decreases and the preference to search for new accommodation is higher, not only in the city but also in other cities in the region. In this respect the study will try to confirm that if the attachment level to the new settlements and to the city is low, it is hindering the recovery process of the city.

Connectivity was selected as the spatial indicator to be developed because it is an indicator of physical dimension, which also influences - and reflects - the social and the economic situation during the recovery phase. Spatial connectivity is therefore seen as a meta-indicator [26] for access to healthcare, education, financial and recreation facilities [27] as well as sources of employment and amenities in the temporal and in the spatial dimension. Spatial connectivity is an indicator of recovery, based on the measurement of the preference level of people to move to another place due to connectivity problems. The desire to move to another place in the city or in the region is a social phenomenon, depending on the advancement of the recovery process; while the attachment to a place, defined as "Topophilia" [28], is the result of experiences, memories and intention of remain due to satisfaction with employment opportunities, basic services, urban facilities, amenities, connectivity and so on, that are not available in the new settlements in L'Aquila. Sterrett et al. [29] elaborate on the role that urban design can have in social issues, related to the socio-economic disconnection and physical disconnection. Also Kevin Lynch [30] considers the paths as a key component of urban structure, because they are a means for accessing other people, services and employment. The traditional town planning proposes to create "social cohesion" through locating facilities in the center of community areas; however, only few of the new settlements in L'Aquila have facilities such as parks or temporal churches that generate physical cohesion.

According to Sterrett et al. [29], it is necessary to understand "the social dynamics of the city" in order to know what works in the urban structure. Using Belfast (Ireland) as a case study area, they discovered that the commercial city center largely supports a daytime economy, which in fact does not exist in L'Aquila anymore. Further, heavy traffic has a representative impact on the health and amenity of the most deprived communities, which is not the case in L'Aquila; and the patterns of movement in Belfast around the segregated areas had the peculiarity of avoiding passing through other community territory, which is also not the case in L'Aquila. Here, the peculiar factor is the isolation level of the new settlements, not only regarding the city but also amongst each other. These depend mainly on private transport in order to have access to other people, services, employment [30] or amenities [27], and generally speaking, social capital and opportunities.

The main objective of this paper is to prove that spatial connectivity can serve as a spatial indicator to monitor and evaluate recovery, which integrates variables such as distance, travel time and quality of the public transport service. The relationship between connectivity and the preference to search for a new site will support the evaluation of the success of a recovery process.

The problem of connectivity in the recovery process of a city can be compared with the human physiology; if after an accident, the blood does not irrigate a part of the body, the organs located in this part will die, causing delay or disruption to the body's recovery process. If there are connectivity problems such as long distances, scarce transport media, roads in poor conditions and long travel times, the flow of goods and services and the supply-chain [10] will be interrupted, like the 
blood in the body, and the interest of travelling between the origin and the destination will decay in the end, affecting the facilities in those places. In this sense, facilities such as stores, supermarkets, banks, industries, schools, post offices and so on, will have not only less visitors, but also supply chain problems. The assessment of the recovery process after the earthquakes in Loma Prieta and Hurricane Andrew indicates that these kinds of problems were significant predictors of poor recovery outcomes [10].

The ability of a household to carry out normal activities is fundamental to assess the advance of a recovery process. One of the key systems associated with the possibility of carrying out daily activities and the reactivation of a city involved in a recovery process are the available means of transportation [31] Transport planners will measure the local and regional traffic flows [12]. We therefore consider spatial connectivity as a key indicator of recovery. In spite that traffic flow is another variable of the spatial connectivity index, its correlation with the desire to move to another place is not taken into account in this paper due to the lack of data about the frequency of buses between each settlement and to the inner city. However, during fieldwork, it was possible to observe that the frequencies of buses en route to Cese di Preturo, Coppito 3 and 2, Sassa and Pagliari di Sassa (some new settlements on the west of the core of L'Aquila), and the city center were very low (around $40 \mathrm{~min}$ ) and not reliable, and the routes themselves were still very confusing, which encourages the dependency on the private cars. With the intention of promoting the use of public transport, and based on consumers` transportation behavior, Bronner [32] carried out a survey among train-travellers and car-travellers about decision styles in transport mode choice. $\mathrm{He}$ came to the conclusion that the reliability of reaching a destination on time is a very important aspect to both population groups, which actually heavily depend on the reliability of the frequency, at least for train-travellers. Other authors such as Jessiman and Kocur [32] revealed in their studies that reliability was the most critical aspect to select a travel mode for a work trip over other variables such as overall travelling time, travel costs, comfort and safety. This finding is very important in regard to L'Aquila, taking into account that work and employment sources are a critical aspect in the recovery process of L'Aquila.

\section{Methodology}

In the previous work, the first step comprised a review of vulnerability and recovery indicators [33]. We take vulnerability indicators identified in the MOVE project as a starting point. The case study areas of Barcelona (Spain), Cologne/Bonn (Germany) and Florence (Italy) are dedicated to identifying earthquake vulnerability indicators. Nevertheless it needs to be emphasized that this does not mean that some indicators are tied to a particular hazard. Rather, some indicators are more relevant to particular hazards and to particular case studies.

The MOVE web-based database accessible at www.movefp7.eu/ contains a total of 260 indicators composed of 220 single and 40 composite indicators. 78 (35\%) of the single indicators are specifically related to earthquakes and $8(20 \%)$ of the composite indicators are also associated with this phenomenon. Another 86 single indicators were identified upon reviewing the literature. However, these were not included in the final set of indicators, in most cases due to the lack of data.

From secondary sources 119 recovery indicators were identified. The sources were (a) books, (b) scientific publications, which address the cases of Kobe and some cities in Italy, (c) from periodical situation reports from Haiti and Chile issued by OCHA, (d) the Magazine "Noi Abruzzo" published by the Commissioner of the reconstruction in L'Aquila (Italy), and the data collected in the MICRODIS project funded under the EC FP6 Programme, with the aim to study the epidemiological, social and economic effects of the earthquake that struck L'Aquila [33].

For both vulnerability and recovery, indicators were aggregated according to the following dimensions of susceptibility: physical, social, economic, cultural, and institutional. Susceptibility is defined as the predisposition of particular areas to be affected by a hazard [8]. The second step was an analysis in order to identify which of these indicators were based on spatial variables or which ones can be spatially mapped. The third step was to find the common variables among the subsets of spatial variables from vulnerability indicators and the spatial variables from recovery indicators. The fourth step is more pragmatic, but may sometimes limit the methodology and the respective results significantly: it is an investigation of the availability of data needed to carry out both spatial and statistical analyses and, subsequently, to determine the most suitable techniques in both cases.

This methodology brings us to some partial results, in which some indicators have been identified. Nevertheless, for the purpose of this study only indicators related to urban facilities and land use were considered due to their relation with the connectivity index.

In the course of the MICRODIS project, the new settlements to which homeless people from L'Aquila were relocated were geo-referenced. MICRODIS [34] extracted data from a housing demand census, where 153 people from different households were requested to rank their preference of searching for a new settlement. The MICRODIS project compared the number of families located in sites that were not in their first choice, and also interviewed people, who considered the site in which they were relocated, as the worst option and were currently looking for a new place to live. Based on the data collected and processed, they developed the index of site preference. The households were relocated in the new settlements, far away from their former houses, because they were originally located inside the restricted zone.

The hypotheses to be tested states that while the connectivity between the new settlements and the inner city in L'Aquila decreases, the number of people who prefer to search for new accommodation increases, not only in the city but also in other cities in the region. The distance decay function states that while the distance to a destination increases, the interest to reach this point decreases. Spatial connectivity is defined as an indicator made up of variables such as distance, travel time, quality of the public transport (number and reliability of frequencies), which guarantee the access to other people, services [27] and opportunities to commute between the new settlements and the inner city; however, the data analysis is based on the distance and the travel time because there is not enough information available about the frequencies of public transport in this area. In spite that at a first glance distance and travel time are almost the same, it is important to observe that while 
distance is a fixed variable, only influenced by the topography of the terrain, the travel time can change according to the number of buses and the reliability on the bus frequencies, conditions of the roads, speed limits, characteristics of the car, the ability of the driver and the specific conditions of the mobility in the region.

During the fieldwork carried out in April, 2010, according to the experience of the authors, it was possible to assert that the public transport service was scarce, the frequencies were low (as presented in Fig. 5), and its regularity not reliable, and hence the accessibility to new settlements depend mainly on private transport.

In the case of L'Aquila, the entire historical city center was formerly also the central business district of L'Aquila. This area was cordoned off and residents can only visit their houses occasionally for short durations. The land use and the restricted area in L'Aquila are shown in Fig. 6 and pictorially in Fig. 7.

Based on data collected during the MICRODIS project using GPS devices, the locations of the new settlements were obtained. The shape file containing these new locations was exported into a Google Earth format (KMZ) file. The nearest road to the settlement was identified in Google Maps using not only the vector road network overlaid to the satellite images, but also interpreting the satellite images, supported by the knowledge acquired during the fieldwork. Subsequently, the respective distances and travel times between the 19 new settlements and the inner city of L'Aquila city were estimated,

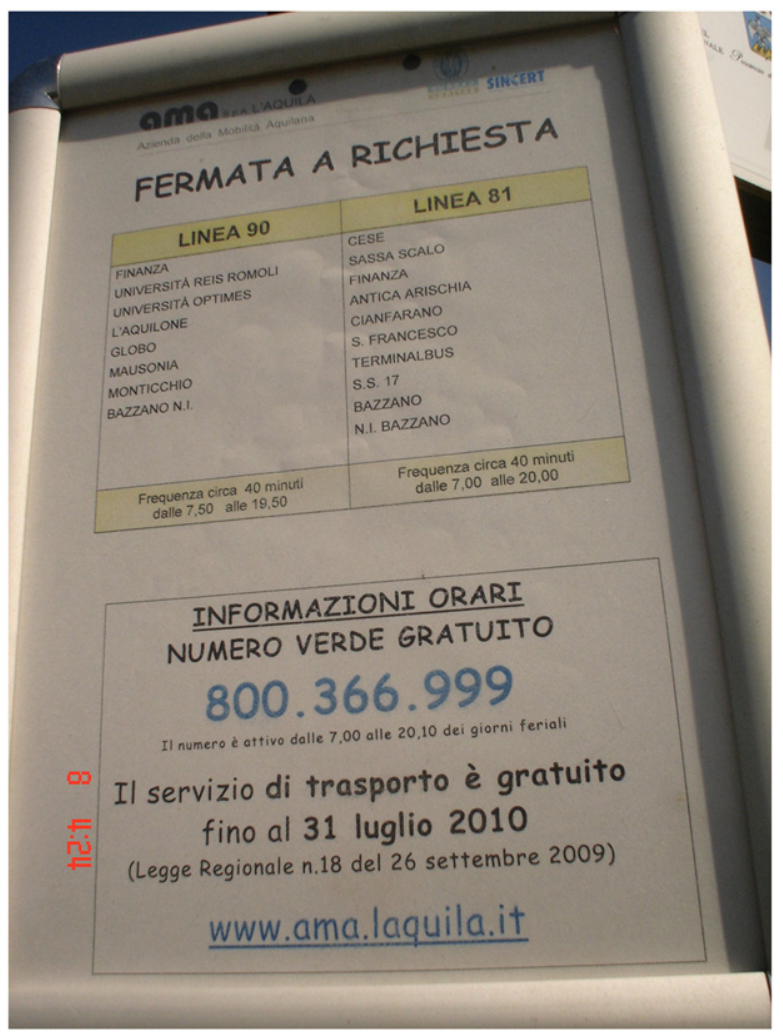

Fig. 5. Frequencies of the public transport to the new settlements located in the west of the inner City of L'Aquila. April 6th, 2010. Frequencies every 40 min between 7:00 and 20:00. taking the access to each new settlement as the origin point. The selected destination point was the Piazza del Duomo, due to its nodal character, being the center of economic activity for the city and even the region. A node is defined as a strategic point in a city which people can enter and have access to, or find transport [30] to reach several other places. It is a place characterized as a large palette of different activities. Fig. 8 shows an example of how the distance between Cese di Preturo (new settlement) and Piazza del Duomo was estimated. In cases, when there was more than one suggested route with two or more distances and travel times from the origin to the destination point, the shortest distance and travel time were selected.

Piazza del Duomo was selected as a destination point due to its geographical centrality of the study area. Furthermore, it is almost an equidistant point to all new settlements, and the business center of L'Aquila used to be located around this main square as shown in Fig. 9. Today, it is bordered by the restricted area, as depicted in Fig. 8. The number of people in each settlement who prefer to search for another place in each new settlement is displayed in Fig. 10. The results comparing the values of distance and travel time, to the number of people who prefer to search for another site for every settlement are presented in Table 1.

\section{Results}

We can express the relationship between variables statistically by looking at two measures: covariance and the correlation coefficient. Before conducting the correlational analysis, we used a matrix scatterplot to interpret the general trend of the data, comparing the number of people with the preference of searching for another place in each new settlement to the distance, and the travel time to go to the inner city.

The resulting matrix scatterplot is depicted in Fig. 11. From this matrix it is possible to observe that the number of people with the preference of searching for another site increases with the distance. Prolonged travel times required to commute between the new settlements and the inner city of L'Aquila yield the same results. Logically, the distance and the travel time are directly related.

Since the correlation to be tested is between two variables, thus being the number of people with the preference of searching for another site against distance, and the number of people with the preference of searching for another site against travel time, bivariate correlation is used [35]. The test will be one-tailed for each hypothesis related to the connectivity: "the greater the distance between the new settlements and the inner city of L'Aquila, the higher the number of people who prefer to search for another site", and "the longer the travel time between the new settlements and the inner city of L'Aquila, the higher the number of people who prefer to search for another site". Considering the fact that this study deals with parametric data, Pearson's correlation is applied.

In spite that the correlations are a powerful research tool, it is still essential to perform a regression analysis in order to test the predictive power of the variables chosen. The correlation coefficient does not give any indication about causality; therefore, the coefficient of determination $\mathrm{R} 2$ is used to measure the amount of variability in one variable, which is explained by the other [35]. 
LAND USE CLASSIFICATION BEFORE THE EARTHQUAKE IN L'AQUILA (ITALY)

Adapted from Servizio per I'Informazione Territoriale e la Telematica -Ufficio Sistema Informativo Geografico-Regione Abruzzo
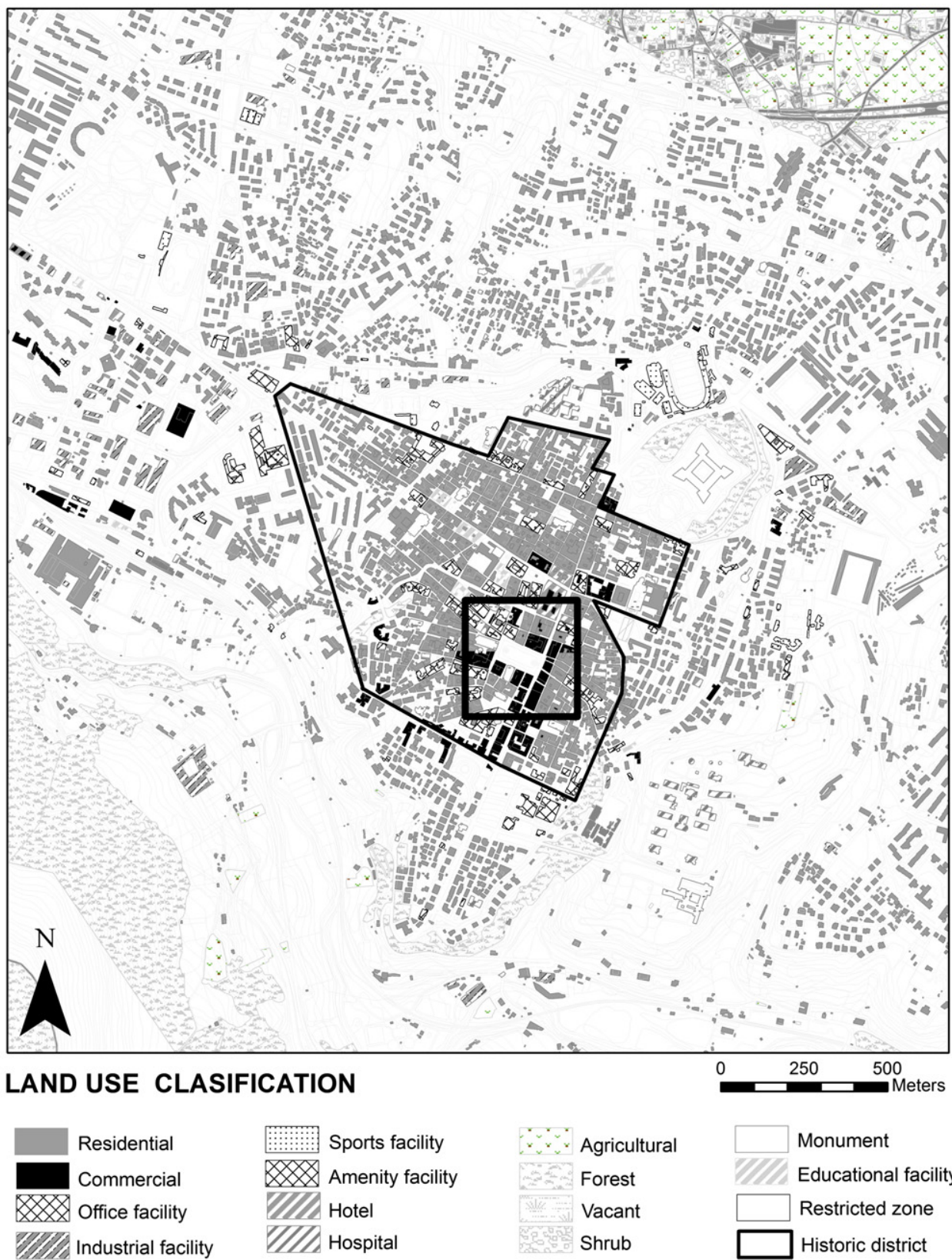

$\begin{aligned} & \therefore \text { Agricultural } \\ & \text { Vorest } \\ & \text { Vacant } \\ & \text { Shrub }\end{aligned}$

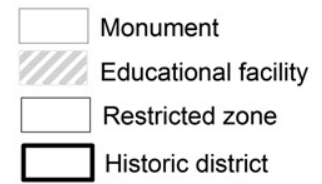

Fig. 6. Land use classification before, and cordoned off - restricted area after the earthquake in L'Aquila (Italy). Adapted from Servizio per l'informazione territorial e la Telematica - Ufficio Sistema Informativo Geografico-Regione Abruzzo. Land use classification before the earthquake, and restricted area afterwards in L'Aquila (Italy). Adapted from Servizio per l'informazione territorial e la Telematica - Ufficio Sistema Informativo Geografico-Regione Abruzzo.

At a first glance at the data, it was possible to demonstrate the correlation between the number of people who prefer to search for another site and the distance and travel time between the new settlements and the inner city of L'Aquila using the matrix scatterplot depicted in Fig. 11. Limtanakool, N. et al. [27] also identified a set of variables, which can influence the mode choice for medium and longer-distance trips (longer than $50 \mathrm{~km}$ ), such as the socio-economic characteristics of travelers, the spatial configuration of land use, and the transport infrastructure at the origin and destination, among others. These variables can also influence not only the preference of searching for another site, but also the spatial connectivity in the case of L' Aquila. Gender, age, household structure, income, education level, and car availability are some of the socio-economic characteristics that can influence the preference of searching for another site, and they can be considered for further research. Along the same line, 


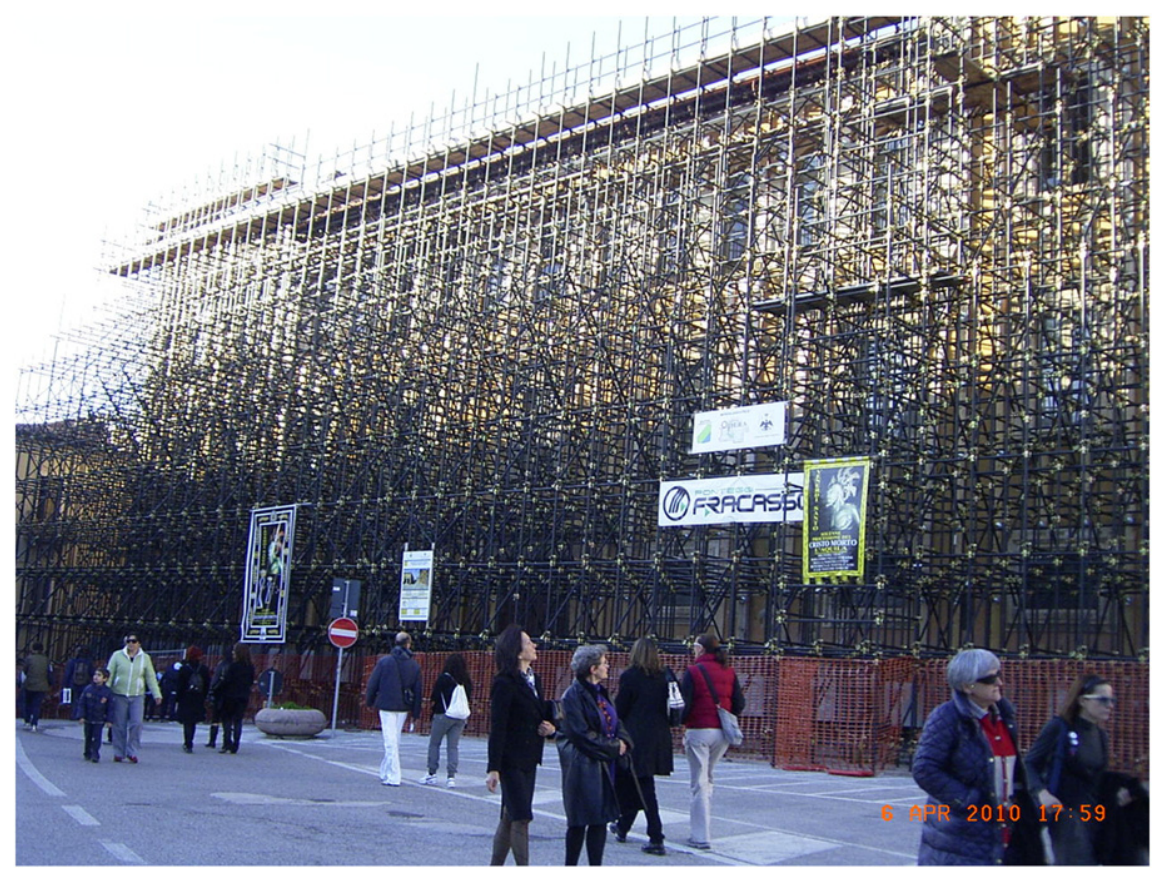

Fig. 7. Cordoned off area in the former business center of L'Aquila city (Italy). April 6th, 2010 (one year after the earthquake).

density, proximity to infrastructure, and land use diversity can influence connectivity, since aspects such as higher population densities mean high demand for public transport, and hence better developed public transport networks. Additionally, higher densities and closer facilities ease the access to public transport, encouraging the use of public transport [27]. Unfortunately, this is not the case in L'Aquila, where neither the density of new settlements is high, nor the facilities in close proximity to them.

Regarding the land use diversity, Cervero and Kockelman [27] reached the conclusions that the use of public transport encourages land use mixing. The easy access and egress time from the railway station or the bus stop to a variety of land uses make transit attractive not only for working, but also for leisure trips. Maybe these results contribute to the idea that scarce public transport does not encourage the location of services, facilities, amenities or sources of employment around the new settlements in L'Aquila; however, it could be the other way around, that the lack of land use diversity makes the investment on improving the public transport unattractive.

\subsection{Correlation analysis}

In Table 2 can be observed that each variable is perfectly correlated with itself and it appears in the table as $r=1$ along the diagonal of the table. The number of people who prefer to search for another site is positively related to distance with a Pearson correlation coefficient of $r=0.71$. The output also shows that the number of people with the preference to search for another site is also positively related to the travel time, with a coefficient of $r=0.76$. In both cases, there is less than .01 probability that a correlation coefficient this large would have occurred by chance in a sample of 153 people interviewed in 19 new settlements (as indicated by the asterisks after the coefficient). This significant value tells us that the probability of this correlation being a coincidence is very low, in fact close to zero. There is a genuine relationship between the number of people who prefer to search for another site and the distance and travel time between the new settlements and the inner city.

\subsection{Regression analysis}

\subsubsection{Distance against preference to search for another site}

The summary of the model provided by SPSS is presented in Table 3. This table presents the value of the correlation coefficient or R and the derived R2 for the model. For the regression of distance against the number of people who prefer to search for another site, $R$ has a value of 0.71 . The value of $R 2$ is 0.518 which demonstrates that the distance between the new settlements and the inner city accounts for $51.8 \%$ in the preference of people to move to another place; in other words, to explain the reason why some people are searching for new places to live, it is necessary to have a look at the distance that they have to travel every time that they need to go into the inner city. There could be other reasons to explain that preference, however, this model which includes only the distance from the new settlements to the inner city, can account for almost 52\%. This means that the remaining 48\% must be explained by the previously mentioned reasons such as the stagnation of the economy, the lack of sources of employment, the lack of enough urban facilities, services or amenities or the desire to go back to live at the city center.

\subsubsection{Travel time against preference to search for another site}

For the regression of travel time against the number of people who prefer to search for another site, Table 4 shows an $\mathrm{R}$ 
value of 0.76 and the value of $R^{2}$ is 0.584 which demonstrates that the travel time between the new settlements and the inner city accounts $58.4 \%$ of the preference to move to another place. This means that $41.6 \%$ of the people with a preference to search for another site can be put down to the previously mentioned variables.

If a regression analysis between the variables travel time and distance is performed, Table 5 shows that the R2 is 0.704 ,

a
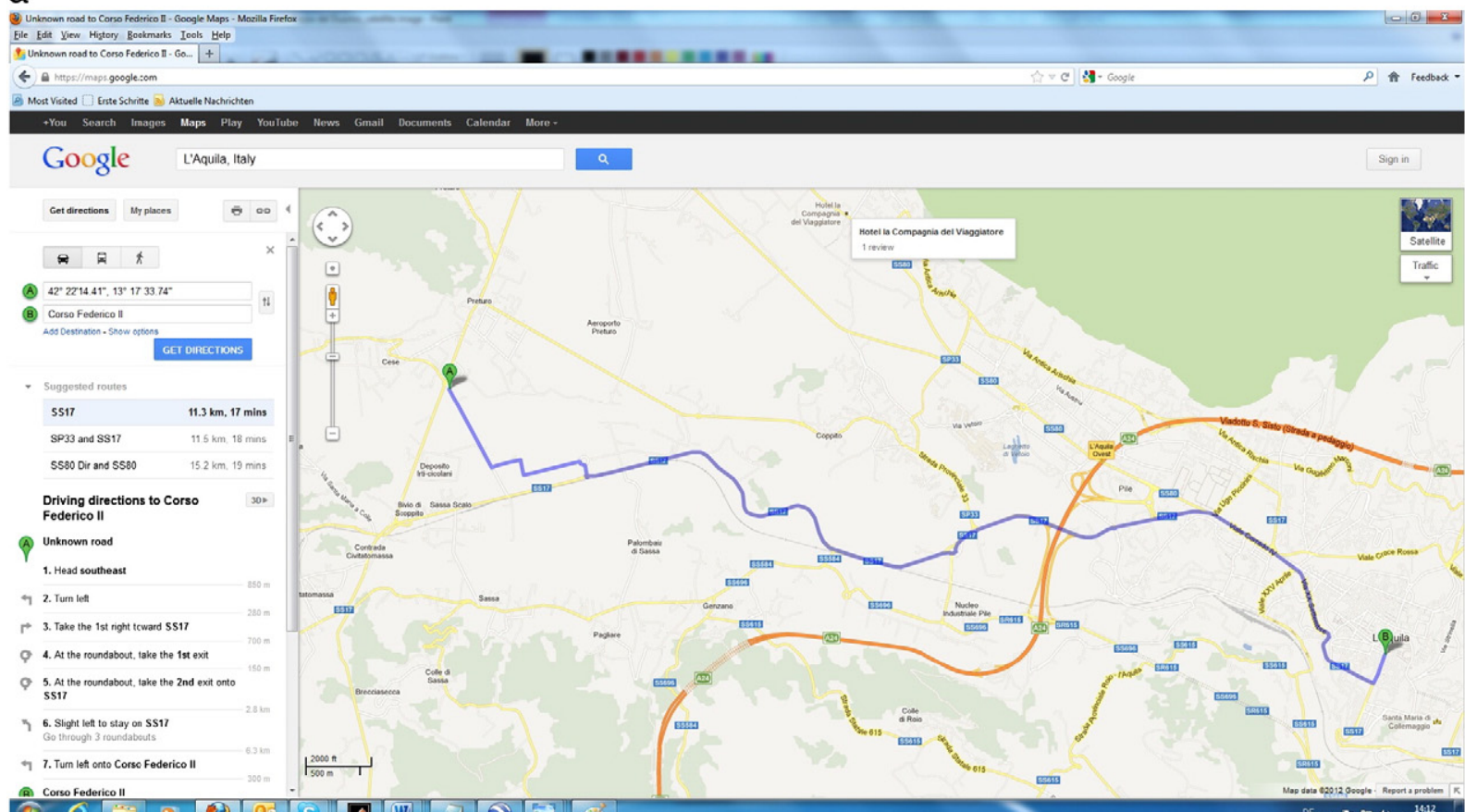

(e) 0 (3)

b
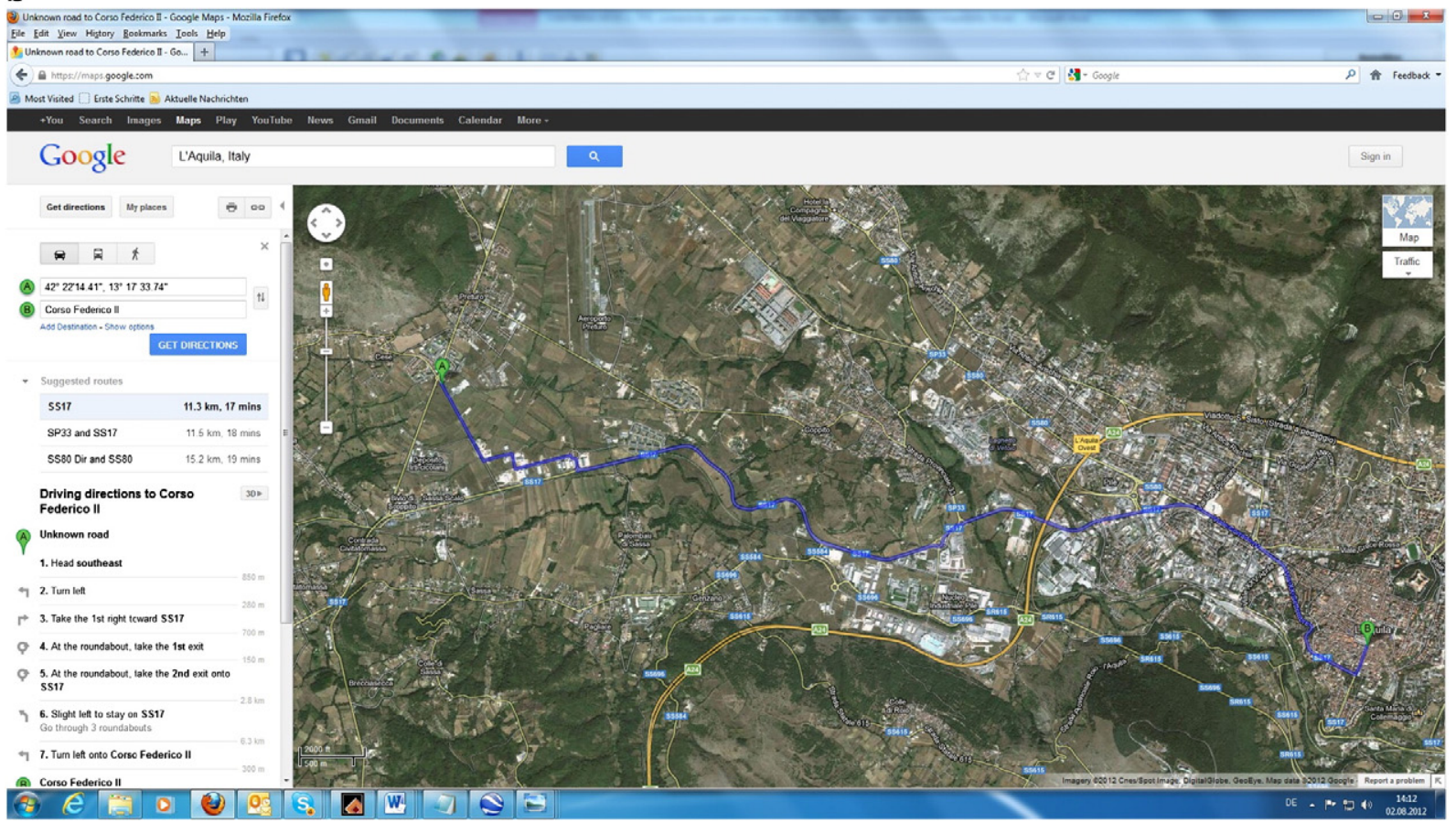

Fig. 8. Distance and travel time estimation exercise between Cese di Preturo (new settlement) and Piazza del Duomo in L'Aquila (Italy); a) vector road network; b) vector road network overlaid to the satellite images; c) Reference Point in Cese di Preturo; d) Reference point in Piazza del Duomo. 
C
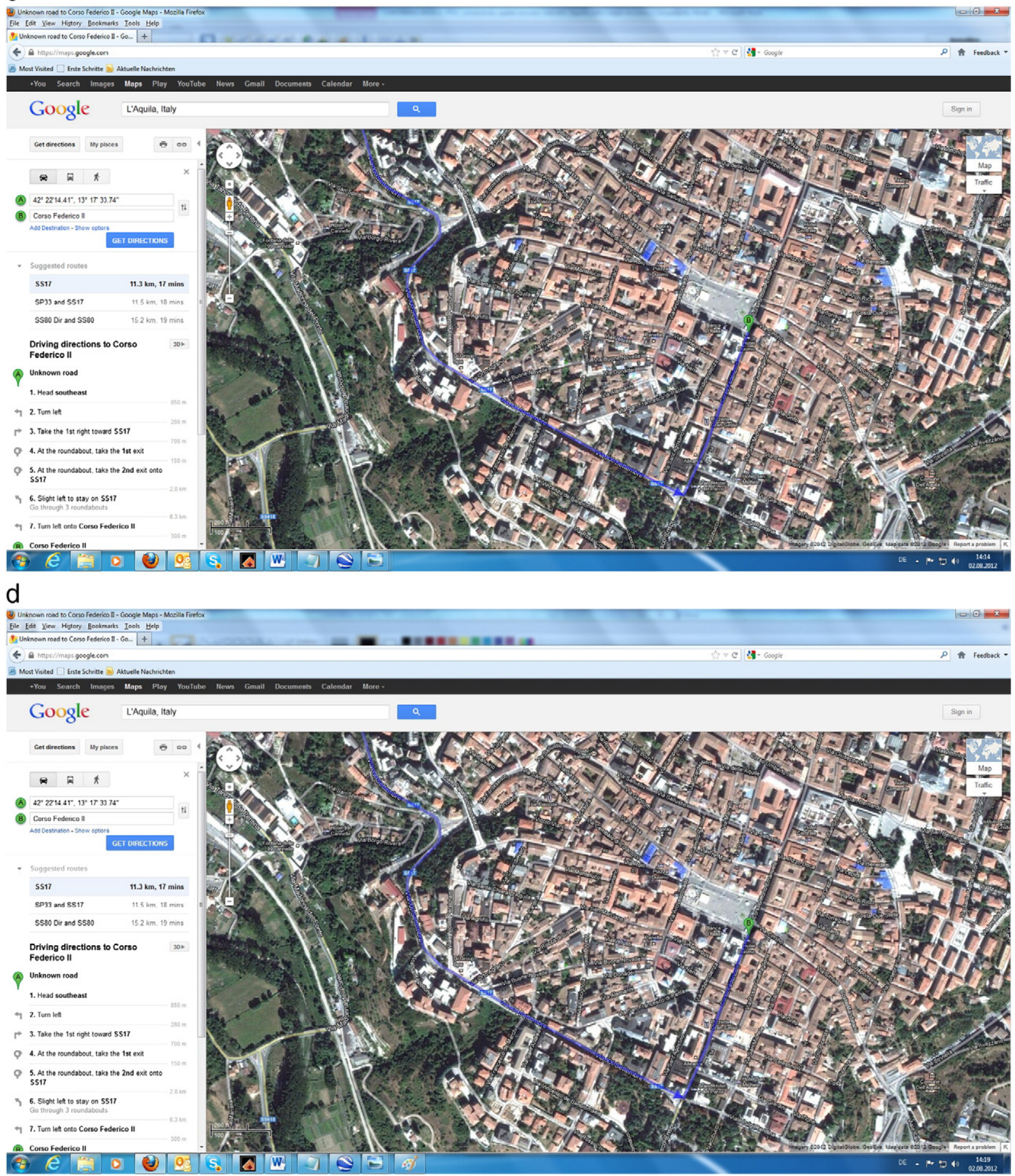

Fig. 8 (continued)

which tells us that distance can account for $70.4 \%$ in the variation of the travel time, as it is presented in Table 5 . This means that $29.6 \%$ of the travel time must be explained by the influencing factors mentioned at the beginning. According to [27] Koppelman includes the travel time in its study about mode choice for inter-city travel. Bel concludes that adding travel time considerations improves the explanatory power of the model for inter-city mode choice, and hence he recommends taking this factor into account in order to study the demand for inter-city travel, which is almost the current situation of L'Aquila taking into account the long distances between the inner city and the new settlements [27]. 


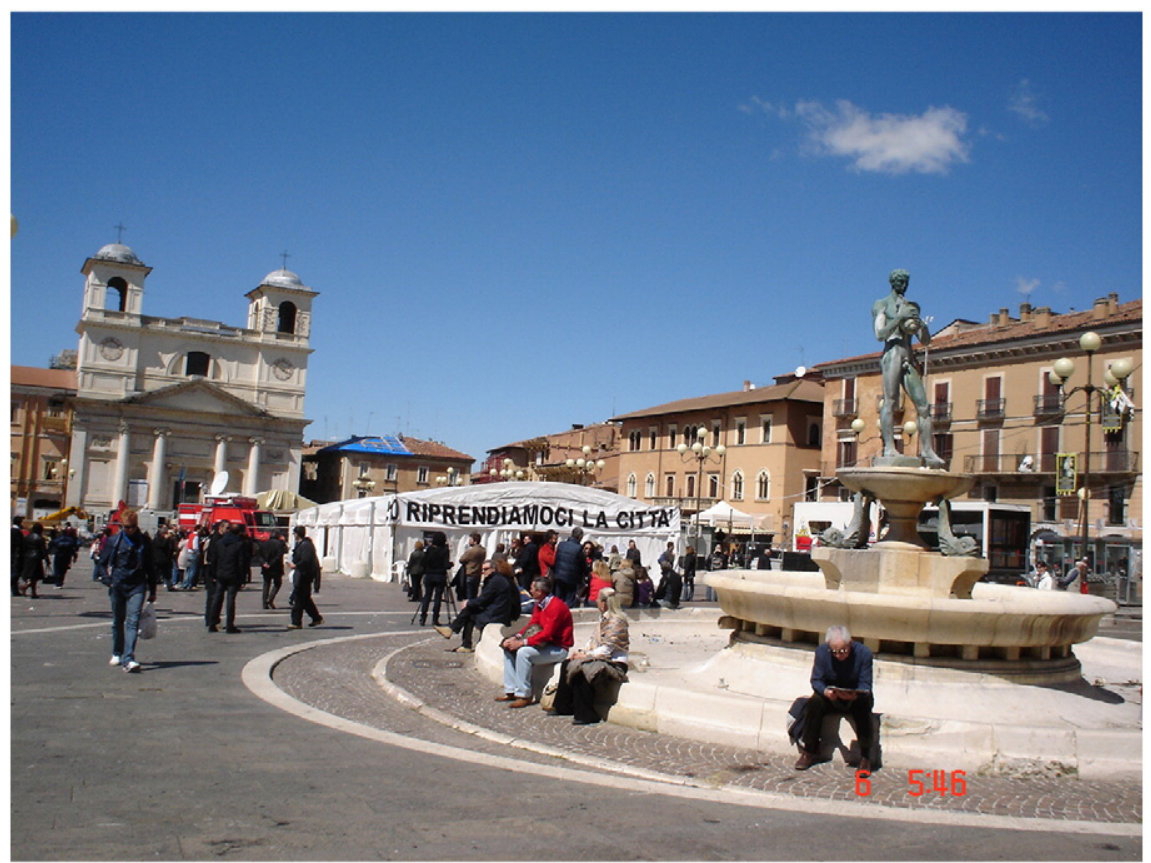

Fig. 9. Piazza del Duomo in L'Aquila city (Italy). April 6th, 2010.

\section{Discussion}

It was mentioned in the methodology section that the correlation coefficient is a measure of the linear relationship between variables; however, it does not show any indication of causality. In this case, although it is possible to conclude that the preference to search for another place increases when the distance and travel time from the new settlements

\section{PREFERENCE TO SEARCH FOR ANOTHER PLACE IN THE NEW SETTLEMENTS, L'AQUILA - ITALY} Based on Servizio per l'Informazione Territoriale e la Telematica - Ufficio Sistema Informativo Geografico - Regione Abruzzo. MICRODIS project - Commission's Sixth Framework Programme.

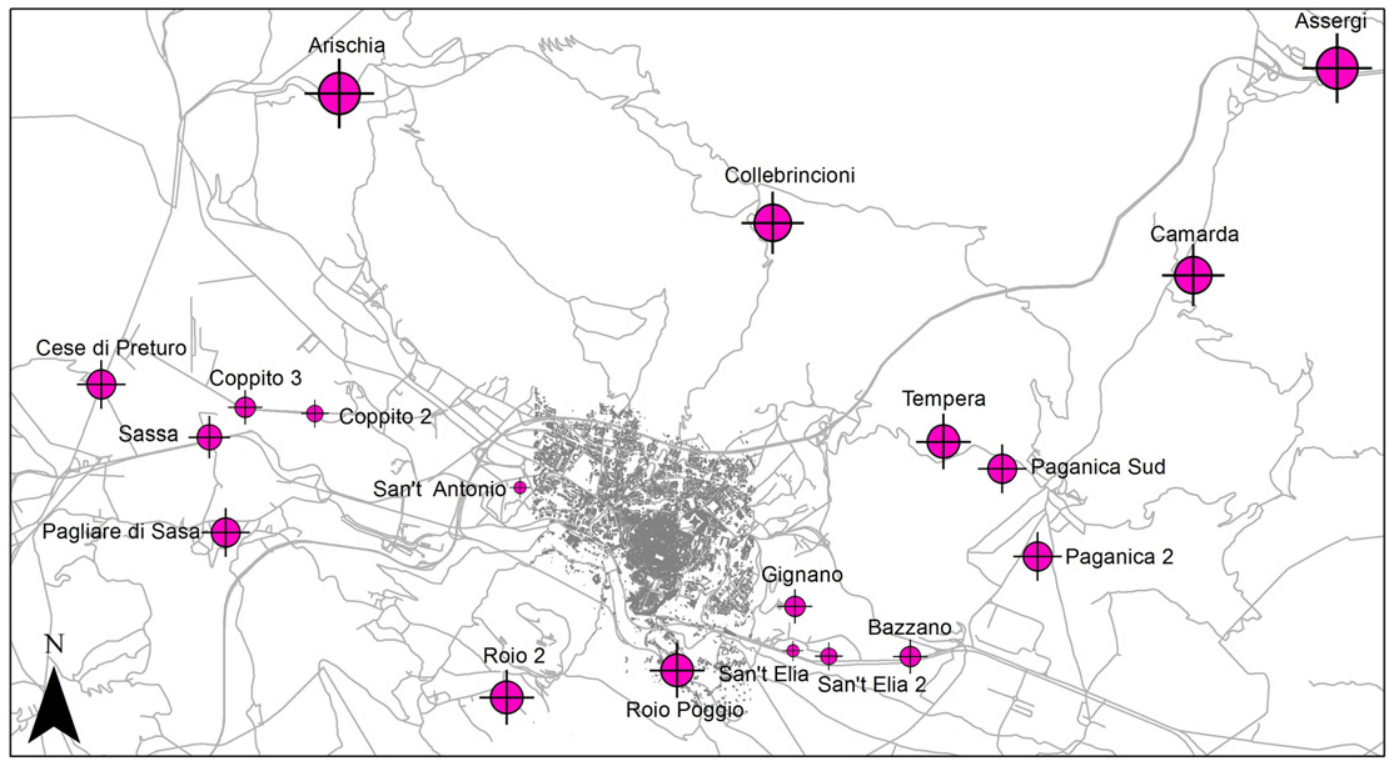

Preference to move to another place

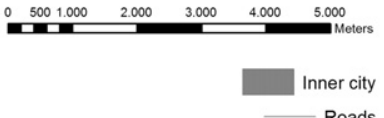

The size of the symbol is correlated with the value of the preference to move to another place.

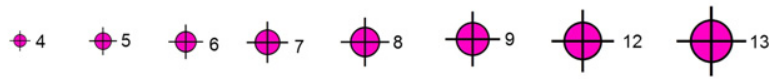

Fig. 10. Preference to search for another site in the new settlements. 
Table 1

Distance and travel time compared with the number of people with the preference to search for another place in each new settlement.

\begin{tabular}{|c|c|c|c|}
\hline \multirow[t]{2}{*}{ Settlements } & Distance & Time & $\begin{array}{l}\text { Preference to search } \\
\text { for another site }\end{array}$ \\
\hline & $\mathrm{Km}$ & Minutes & Value \\
\hline 1 Sant'Antonio & 3 & 6 & 4 \\
\hline 2 Sant' Elia & 8 & 10 & 5 \\
\hline 3 Coppito 2 & 8 & 13 & 5 \\
\hline 4 Sant' Elia2 & 9 & 12 & 5 \\
\hline 5 Gignano & 8 & 12 & 6 \\
\hline 6 Coppito3 & 8 & 14 & 6 \\
\hline 7 Bazzano & 9 & 11 & 6 \\
\hline 8 Sassa Zona Nsi & 10 & 15 & 8 \\
\hline 9 Pagliare di Sassa & 9 & 14 & 8 \\
\hline 10 Paganica sud & 11 & 16 & 8 \\
\hline 11 Cese di Preturo & 13 & 16 & 8 \\
\hline 12 Paganica2 & 12 & 18 & 8 \\
\hline 13 Tempera & 11 & 16 & 9 \\
\hline 14 Roio roggio & 5 & 8 & 9 \\
\hline 15 Roio2 & 8 & 13 & 9 \\
\hline 16 Collebrincioni & 11 & 19 & 12 \\
\hline 17 Camarda & 25 & 21 & 12 \\
\hline 18 Assergi2 & 22 & 19 & 12 \\
\hline 19 Arischia & 15 & 18 & 13 \\
\hline
\end{tabular}

to the inner city also increase, it cannot be said that the long distances and long travel time cause the desire to move to another settlement, to the inner city or even far from L'Aquila. It is important to take into account two reasons: the third-variable problem and the direction of causality.

Any bivariate correlation causality between two variables can be assumed, on the account that there could be several additional variables affecting the result, and these variables had not been considered in this study. In this case, the low and not reliable frequencies of the public transport, the lack of sources of employment, the lack of urban facilities, services or amenities, or even the desire to go back to live at the city center can be further variables which may influence the preference of residents to search for another site. In fact, it is a perfect example of the third-variable problem or the tertium quid, which can be considered in further research.

In the case of the direction of causality, the correlation coefficient does not indicate which variable causes the other to change. It is not possible to assume that the correlated variables, distance and travel time, are the only important ones. Correlation never indicates in which direction the causality operates as such, however, intuition allows us to conclude that long distances and long travel times encourage the preference of residents to search for another site. On the other hand, there is no statistical reason to assume a connection in the other direction and why the preference to search for another site, encourages people to live as far as possible from the inner city of L'Aquila. In spite that the latter conclusion does not make sense because the central business district and hence the urban facilities required in a human settlement is located in the inner city, which is currently the main reason for residents to search for another site to live, the correlation does not prove that it is not true. There is no reason to assume that all people want to move closer to the central business district, however, most people value having urban facilities and amenities close by. This statement is based on the fact that Sant'Antonio is the closest settlement to the core city and the only new settlement which has more than two bus stops, one primary school, one bar, two parks and one sports center; this settlement shows the lowest preference to search for another site, as Table 1 shows. Additional research, based on the secondary data collected by the MICRODIS project, considered the relative importance of urban facilities according to three 


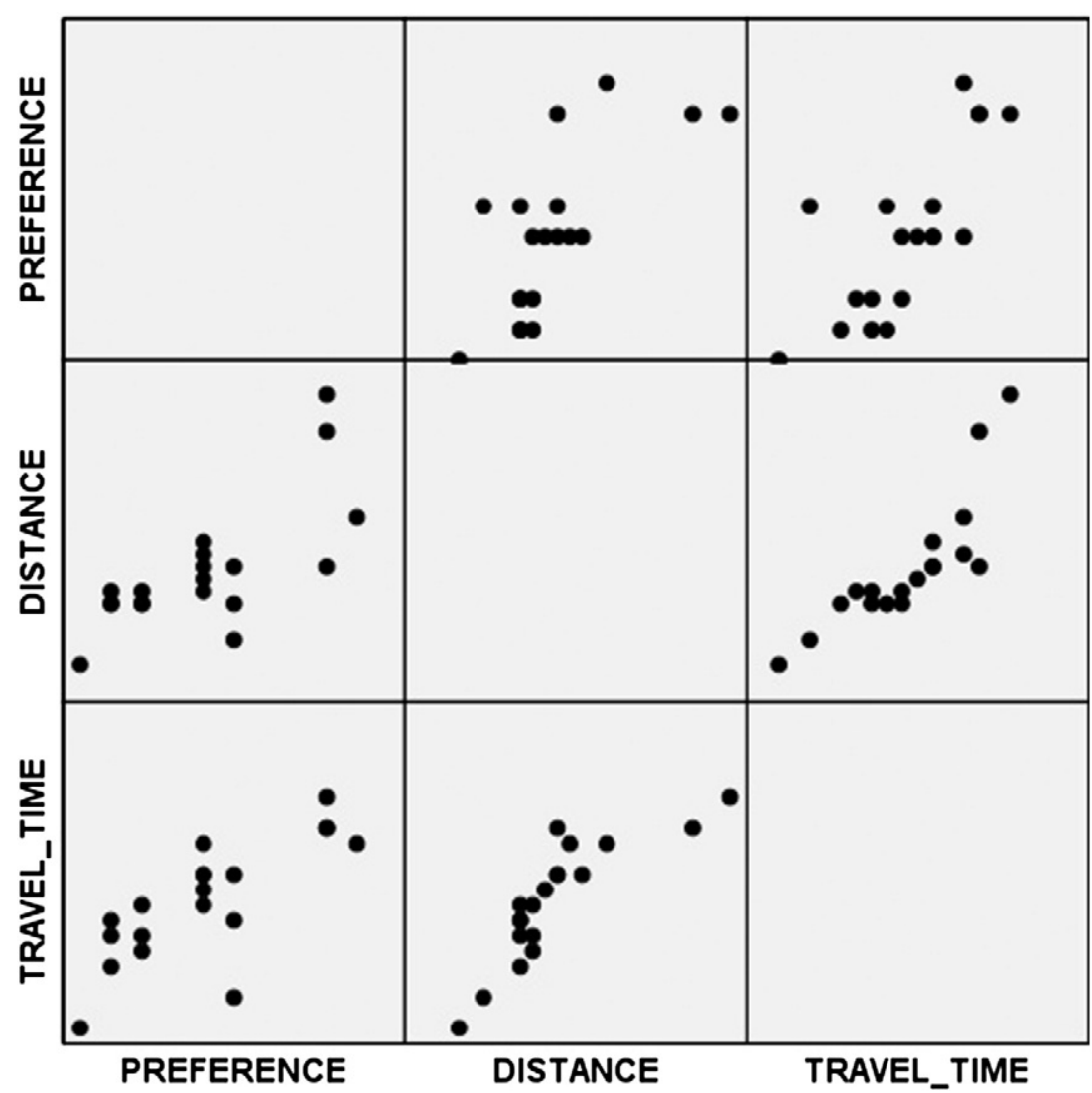

Fig. 11. Matrix scatterplot of preference to search for a new site, distance and travel time to the inner city in L'Aquila (Italy).

categories of users: older people (65 years and above), family (people with children, aged 19 to 64 years) and young people (aged 15 to 18 years); and related those with connectivity. The findings reveal that, on a scale from 1 to 10 , bus stops are more important for older people (10), followed by young people (8) and people with family (6), in spite that when people grow older, they switch from bus trips to private car trips [27], when they are not public transport "captives" e.g. people who do not have a driver license and/or car [32], and taking into account the

Table 2

Output from SPSS for the Pearson's one-tailed bivariate correlation between the preference to search for another site and the distance and travel time between the new settlements and the inner city in L'Aquila.

\begin{tabular}{|c|c|c|c|c|}
\hline & & Preference & Distance & TRAVEL_TIME \\
\hline \multirow[t]{3}{*}{ Preference } & $\begin{array}{l}\text { Pearson } \\
\text { correlation }\end{array}$ & 1 & $.719^{* *}$ & $.764^{*}$ \\
\hline & Sig. (1-tailed) & & .000 & .013 \\
\hline & $\mathrm{N}$ & 19 & 19 & 19 \\
\hline \multirow[t]{3}{*}{ Distance } & $\begin{array}{l}\text { Pearson } \\
\text { correlation }\end{array}$ & $.719^{* *}$ & 1 & $.839^{* *}$ \\
\hline & Sig. (1-tailed) & .000 & & .000 \\
\hline & $\mathrm{N}$ & 19 & 19 & 19 \\
\hline \multirow[t]{3}{*}{ TRAVEL_TIME } & $\begin{array}{l}\text { Pearson } \\
\text { correlation }\end{array}$ & $.764^{*}$ & $.839^{* *}$ & 1 \\
\hline & Sig. (1-tailed) & .013 & .000 & \\
\hline & $\mathrm{N}$ & 19 & 19 & 19 \\
\hline
\end{tabular}

** Correlation is significant at the 0.01 level (1-tailed). low and not reliable frequencies of public transport, as well as the distance to the inner city.

Another example of causality lies in the fact that perhaps the connectivity is not improved because there is no interest or reasons to improve it. As the former central business district in L'Aquila is still cordoned off and the activities which used to take place there have provisionally moved away to other places in the city, in dispersed form and in lesser number, or even to other cities in the province or region, however, not to the new settlements or their close proximities. In fact, they were relocated around the restricted zone as it is portrayed in the pictures in Fig. 12.

It is important to differentiate the acceptance of the hypothesis, and the assessment of specific progress in the recovery, for the case study area. The original hypothesis is: "if the connectivity decreases, the satisfaction with the location of new settlements also decreases and the preference of searching for new accommodation is higher, not only in the city but also in other cities in the region". Connectivity was selected as the spatial indicator to be developed because it is an indicator in the physical dimension, which also influences - and reflects the social and the economic situation. To support the selection of the hypothesis and the indicators, previous research carried out by authors such as Kevin Lynch [30], Limtanakool et al. [27] and Sterrett et al. [29], was considered. Rather than addressing the topic of recovery after an earthquake, these authors tackle the topics of urban structure and the relation between socio-economic disconnection and physical disconnection, 
Table 3

Output from SPSS for the simple regression analysis between the dependent variable: preference to search for another site and the independent variable: distance between the new settlements and the inner city in L'Aquila.

\begin{tabular}{|c|c|c|c|c|c|c|c|}
\hline \multicolumn{8}{|c|}{ Model summary } \\
\hline \multicolumn{2}{|l|}{ Model } & \multicolumn{2}{|l|}{$\mathrm{R}$} & R square & Adjusted R square & \multicolumn{2}{|c|}{ Std. error of the estimate } \\
\hline 1 & & $.719^{\mathrm{a}}$ & & .518 & .489 & 1.92749 & \\
\hline \multicolumn{8}{|c|}{ ANOVA $^{\mathrm{b}}$} \\
\hline \multicolumn{3}{|l|}{ Model } & Sum of squares & df & Mean square & $\mathrm{F}$ & Sig. \\
\hline \multirow[t]{3}{*}{1} & Regression & & 67.789 & 1 & 67.789 & 18.246 & $.001^{\mathrm{a}}$ \\
\hline & Residual & & 63.159 & 17 & 3.715 & & \\
\hline & Total & & 130.947 & 18 & & & \\
\hline \multicolumn{8}{|c|}{ Coefficients $^{\mathrm{a}}$} \\
\hline \multirow[t]{2}{*}{ Model } & & & \multicolumn{2}{|c|}{ Unstandardized coefficients } & Standardized coefficients & $\mathrm{t}$ & Sig. \\
\hline & & & B & Std. error & Beta & & \\
\hline \multirow[t]{2}{*}{1} & (Constant) & & 4.060 & 1.034 & & 3.927 & .001 \\
\hline & DISTANCE & & .370 & .087 & .719 & 4.272 & .001 \\
\hline
\end{tabular}

a Predictors: (Constant), DISTANCE.

b Dependent variable: PREFERENCE.

respectively, and recovery is the rearrangement of the urban structure based on socio-economic and physical connections.

The acceptance of the hypothesis allows the consideration of spatial connectivity as an indicator of recovery, and applies this indicator for measuring the progress of the recovery in L'Aquila.

In this sense, according to the results of the logistic regression analysis, at least in regard to distance, it is possible to accept the hypothesis. Having connectivity as indicator, and using the same data to test the hypothesis, it is possible to measure the spatial connectivity of the recovery in L'Aquila, however, the results are poor, and it is possible to conclude that the progress of the recovery in L'Aquila is still low in the economic and social dimensions. There was no information available about population in each new settlement to model the load of each sector.
However, it would be interesting to conduct further research once the data for modeling the pattern of the traffic flow and including it in a connectivity index, as well as testing the prediction power of this indicator for the preference of moving to another place is available.

Another issue for further research is the lack of urban facilities in the new settlements, which, according to Tierney, can be put down to the following statement: [10] "communities without businesses providing economic opportunities, jobs, goods, and services will in short order lose their populations". This is already happening in L'Aquila because the former central business district is part of the restricted area, and therefore closed. There is currently no predictable date in sight for it to be reopened, due to the strong and expensive scaffolding, which supports the damaged buildings to prevent collapsing when

Table 4

Output from SPSS for the simple regression analysis between the dependent variable: preference to search for another site and the independent variable: travel time between the new settlements and the inner city in L'Aquila.

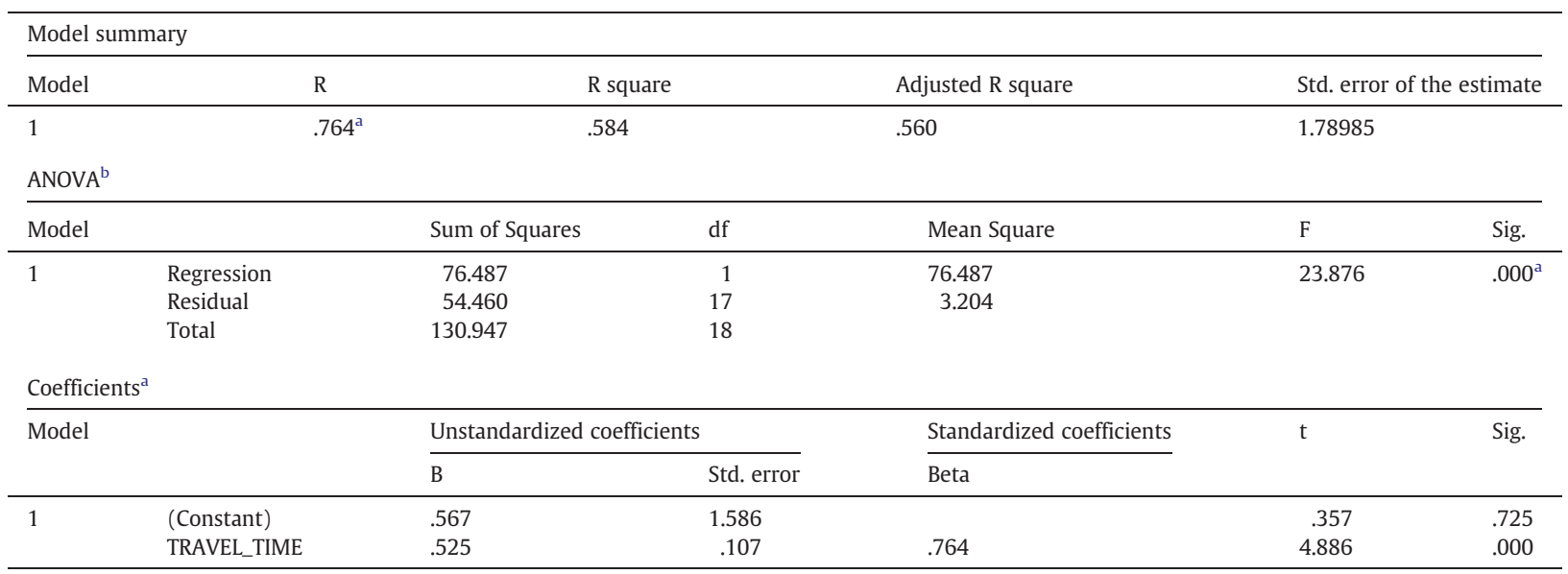

\footnotetext{
a Predictors: (Constant), TRAVEL_TIME.

b Dependent Variable: PREFERENCE.
} 
Table 5

Output from SPSS for the simple regression analysis between the dependent variable: travel time, and the independent variable: distance from the new settlements to the inner city in L'Aquila.

\begin{tabular}{|c|c|c|c|c|c|c|c|}
\hline \multicolumn{8}{|c|}{ Model summary } \\
\hline \multicolumn{2}{|l|}{ Model } & \multicolumn{2}{|l|}{$\mathrm{R}$} & R square & Adjusted R square & \multicolumn{2}{|c|}{ Std. error of the estimate } \\
\hline 1 & & $.839^{\mathrm{a}}$ & & .704 & .686 & 2.20006 & \\
\hline \multicolumn{8}{|c|}{ ANOVA $^{\mathrm{b}}$} \\
\hline \multicolumn{3}{|l|}{ Model } & Sum of squares & df & Mean square & $\mathrm{F}$ & Sig. \\
\hline 1 & $\begin{array}{l}\text { Regression } \\
\text { Residual } \\
\text { Total }\end{array}$ & & $\begin{array}{r}195.400 \\
82.284 \\
277.684\end{array}$ & $\begin{array}{r}1 \\
17 \\
18\end{array}$ & $\begin{array}{r}195.400 \\
9.559\end{array}$ & 40.370 & $.000^{\mathrm{a}}$ \\
\hline \multicolumn{8}{|c|}{ Coefficients $^{\mathrm{a}}$} \\
\hline \multirow[t]{2}{*}{ Model } & & & \multicolumn{2}{|c|}{ Unstandardized coefficients } & Standardized coefficients & $\mathrm{t}$ & Sig. \\
\hline & & & B & Std. Error & Beta & & \\
\hline 1 & $\begin{array}{l}\text { (Constant) } \\
\text { DISTANCE }\end{array}$ & & $\begin{array}{r}7.485 \\
.628\end{array}$ & $\begin{array}{r}1.180 \\
.099\end{array}$ & .839 & $\begin{array}{l}6.343 \\
6.354\end{array}$ & $\begin{array}{l}.000 \\
.000\end{array}$ \\
\hline
\end{tabular}

\footnotetext{
a Predictors: (Constant), DISTANCE.
}

b Dependent Variable: TRAVEL_TIME.

people are walking in close distance. An opposite approach can be observed in the recovery process after the earthquake in Mexico in 1985: rather than orientating their efforts to provide housing, the government worked toward the restoration of the economic services and activities. As a consequence shelter was considered a minor issue to be resolved and homeless people rejected decisions while complicating the distribution of the scarce resources since the government had not accepted foreign financial support [13].

According to previous experiences of recovery after earthquakes in Italy, the disasters exacerbate previous conditions, and while rich areas were successful in their recovery process, areas facing economic problems before the event had gained even more problems due to the event [36]. L'Aquila belongs to the latter category and according to David Alexander [4] there is a backwater in the economy and therefore recovery will be a slow process.

One of the emergent problems since the early recovery phase in L'Aquila was the degradation of the infrastructure, services and loss of productive employments [4]. The city center is decaying behind the cordons and electro-soldier scaffold, while buildings that in past times hosted banks, hotels, stores and so on, remain empty. Nevertheless, this is an example of a chicken-and-egg problem. It is not possible to contend if the spatial connectivity is deficient due to lacking activities in the city center; or if the connectivity problems do hamper the recovery of the city center. In fact the inactivity of the city center itself is an indicator, which shows the negative value of the progress of the recovery in L'Aquila. In this paper, Piazza du Duomo was selected as the destination point; nevertheless, other nodes such as the University of L'Aquila, which is the main employer in the region, can be used as destination point during further studies. However, the question is: which one comes first? - The spatial connectivity or the sources of employment and/or urban facilities? This is not an easy question to be answered, when there is no pre-impact recovery plan in place, or when the recovery plan is not formulated in a participatory way.
Other reasons for residents to search for another site, besides the employment reduction is the decrease in the economic activity, the limited fiscal incentives for employment and the lack of urban facilities around the new settlements. Large numbers of professional people have left the area, the enrolment at the schools has decreased and the enrolment fees of the university have been suspended [4]. Due to these aspects, and with a reduction in the number of inhabitants, it is not possible to talk about advance or success in a recovery process. According to Carola Hein [37] the creation of new towns was a recovery strategy during the postwar period; nevertheless, the declination in urban population, limited the new developments to the already existing lands. This experience demonstrates the dubious success of the urban recovery strategy in L'Aquila, where people were sent out of the inner city to new settlements, although the urban population was already declining before the earthquake.

Besides improving the connectivity it is urgent to reactivate the central business district in the inner city of L'Aquila as soon as possible, in order to have people, services [27] and opportunities as reasons to commute, according to the definition of the spatial connectivity indicator. It is a play of synergies, if the central business district is active again, many sources of employment will appear, people will have reasons to stay in L'Aquila, and eventually the economy will start to function again. This is the only way to achieve an effective recovery, rather than simply providing housing for the homeless, because if people have housing but no employment then they have to leave the city anyway, and as it was stated before, without people, there is no city, there is no recovery.

Unfortunately, previous global experiences demonstrate that missed opportunities to improve resilience and capacity building, also constitute opportunities for the emergent vulnerability [38]. The degree of damage caused by the L'Aquila earthquake shows that the area is located within a highly vulnerable zone [39], and the results of the recovery presented in this study demonstrate that emergent vulnerability in social, economic and institutional dimensions is still not properly addressed by the Italian Government. 
a

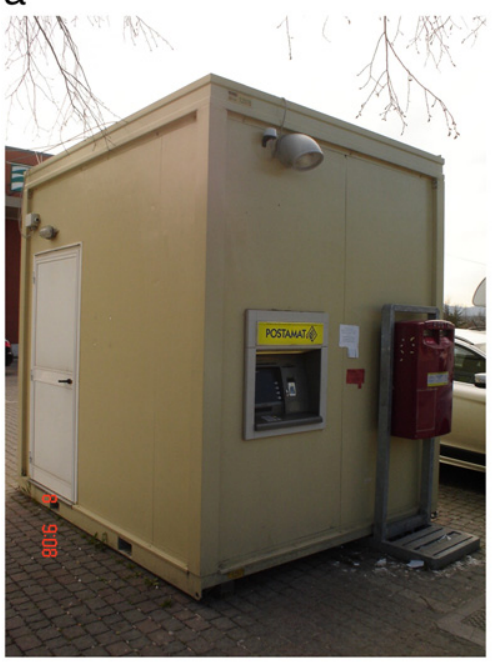

b

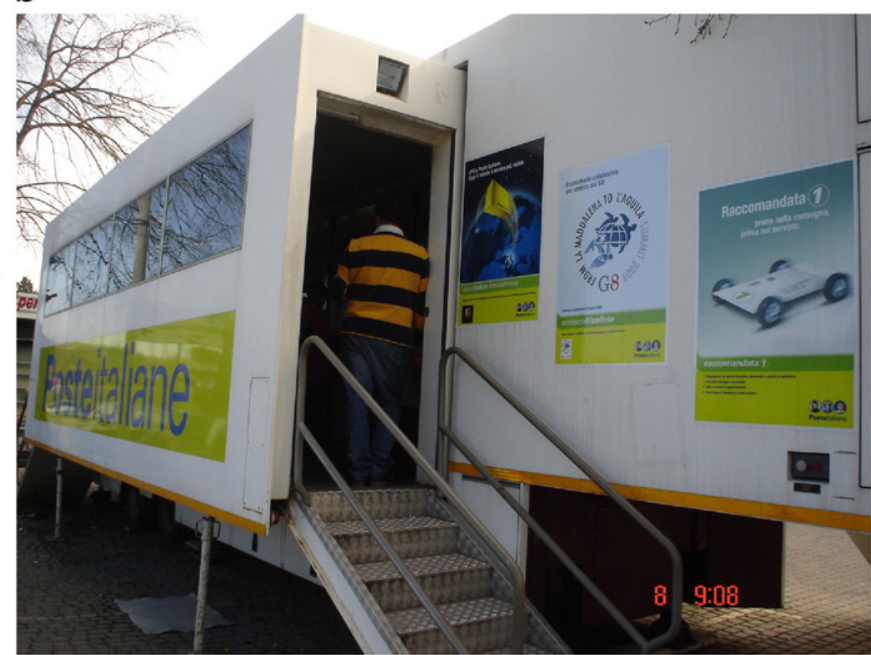

C

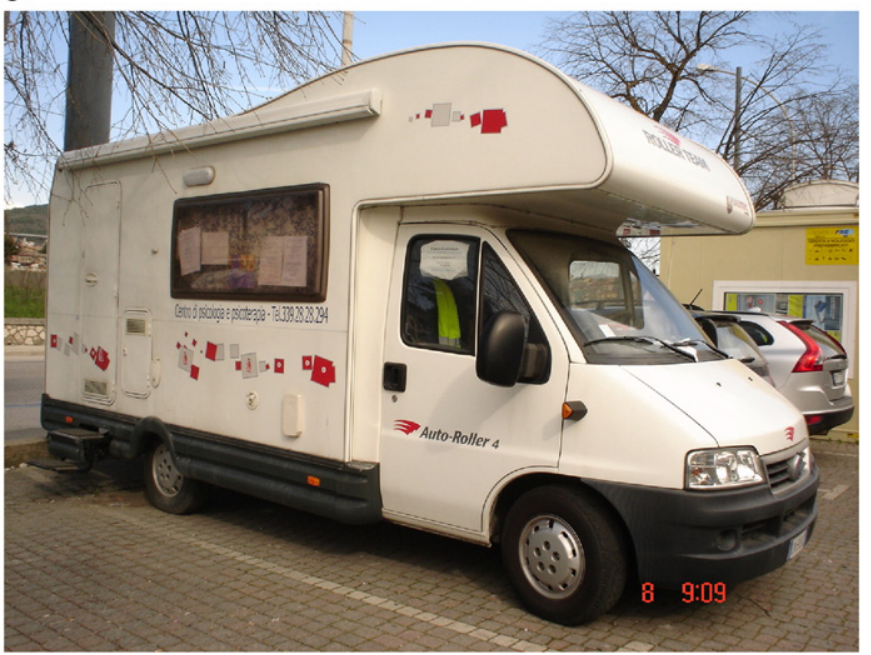

Fig. 12. Provisional urban facilities around the restricted zone in L'Aquila (Italy); a) cash machine; b) post-office and c) psychological counseling center and psychotherapy. (Diana M. Contreras M.).

Miles \& Chang [10] have started a research project aimed at optimizing the recovery process through organizational and communal decision-making in relation to interdependencies among infrastructural elements, households, neighborhoods, businesses, and local economies. Hein [37], based on the reconstruction case after the Great Kanto earthquake, argues that urban change and development depends on both private and public intervention and interaction, besides the current political, economic, social and cultural conditions. This strategy would have been a good option, in the case of L'Aquila, where the decisions have been solely in the hands of the government represented by the national Department of Civil Protection (DPC) [39] in the middle of an economic crisis, taking advantage of the lack of the political weight of L'Aquila [40]. All the problems to be solved related with the recovery itself, and with the decision-making process could have been avoided or at least better managed, having formulated a Pre-impact Recovery Plan [10], as it has been done by cities such as Los Angeles (USA) [41] and Bogotá D.C. (Colombia) [42]. Pre-impact Recovery
Plans are key components of the planning and foresight methodologies for emergency preparedness and management.

\section{Conclusions}

In spite of the fact that the earthquake occurred three and a half years ago, and big advances have been made in respect to housing, it is possible to state that L'Aquila is still in an early recovery phase [43], phase II [20], or restoration [44-46]. The relocation of most of the homeless people after the earthquake is not a proof of recovery; in successful recovery cases such as Kobe, the community was asked to identify the essential factors to promote recovery, and in spite that housing was at the first place, other factors such as social ties, community rebuilding, physical and mental health, preparedness, economy, livelihood, economic and financial situations, and relationship to government were also considered determinant for the promotion of the recovery [47]. In the case L'Aquila, a large degree of 
the economic activities take place in the central business district, which it is still located in the cordoned-off area.

Even though the housing issue appears to be solved at first glance, which is a characteristic of the recovery phase, the problems with urban services, facilities, amenities and transport are yet to be solved [46] the topic of this paper, besides addressing the problems with the management of rubble in the city center. It is possible to state that rather than determining recovery phases according to periods of time, they must be characterized according to activities, variables or indicators. Every recovery case is different according to the financial resources available, the political context, the degree of resilience and the vulnerability level existent before the event. As described in the introduction, the vulnerability level in L'Aquila was very high, which possibly explains the low advance in its recovery process.

Reducing the set of indicators to the indicators represented in a spatial context and the indicators with common features of vulnerability and recovery indices - as suggested in our methodology - bears the risk of ignoring some important single indicators. Nevertheless, the added value of using indicators based on spatial variables for monitoring and evaluating a recovery process relies on the opportunity of planning during the early recovery, and then visualizing the progress of the recovery to the community. Spatial indicators facilitate a participatory process, which is a key issue in a successful recovery [47], and has been totally lacking in the case of L'Aquila [7]. Authors such as Frandberg and Vilhelmson observed that personal mobility is an important aspect in the spatial transformation of developed economies [27].

In this methodology we argued for spatially explicit indicators. In most cases they rely on physical aspects whereas the recovery indices must look beyond the physical aspects in order to reflect the social and economic conditions of people throughout the recovery process [33]. In this present research, it was found that spatial connectivity can be a physical indicator, which contributes to describe quantitatively parts of the dynamics in social, economic and even institutional dimensions, affecting the whole recovery process. In spite that it is difficult to probe the relationship between the physical dimension and the social and economic dimensions, it is necessary to recognize that the progress in the physical dimension is essential in order to promote the progress in the other ones.

The correlation analysis demonstrates that there is a positive correlation between the preference to search for another site and distance. For travel time, the regression analysis confirmed that distance and travel time largely explains the preference of residents to search for another site.

In summary, the spatial connectivity made up of distance and travel time counts for $55 \%$ in the preference of people to move to another place, which proves that in spite not being the predominant factor in the level of dissatisfaction with the new settlements, it is still an important aspect.

As it was stated by Peacok et al. [31] the possibility to carry out normal activities is a fundamental aspect in order to evaluate the success of a recovery process, and this depends to a large degree on the spatial connectivity into the urban settlement. Cassidy claims that if the temporary housing is located in a peripheral area, a frequent and cheap bus service is necessary [48]. The importance of the spatial connectivity lies also in the fact that rebuilding a city implies reconnecting the social networks embedded in schools, offices, sport facilities, supermarkets, theaters, churches and so on. Trying to connect the new settlements, called "towns" [6] for some authors, or "villages" for other others, to the core city cannot be achieved simply just building by building, it must be done neighborhood by neighborhood, and district by district [46]. People accepted to stay in the new settlements because they became homeless after the earthquake, and they still do not have any other housing option, since the second phase of reconstruction has not yet begun. Rather than waiting for the begin of the new phase of reconstruction, some inhabitants of L'Aquila are considering the possibility of emigrating to other cities, taking into account the problems in the new settlements and the economic stagnation of the city. Nowadays the archaeologist Salvatore Settis calls L'Aquila, "the Pompeii of the 21st century" and Eva Clausen a "ghost city" [49].

When authors such as Hogg [45] and Karatani \& Hayashi [20] describe the specific recovery process being studied, they divide the post-disaster period into four phases. UN [43] also divides this specific period into four phases. However, all of them suggest a different time slot for each phase, which each author also denominates in a different form. In the present research, it is concluded that since these phases do not have crisp boundaries it is better to delimit a phase according to the goals achieved in the area affected by the earthquake, rather than to limit each phase to a period of time. Nevertheless, it is considered that there must be specific times in the post-disaster period to make an assessment based on indicators, in order to determine the stage of the recovery process achieved. One of those indicators is the spatial connectivity and the specific time periods where the assessment of the recovery process takes place, namely after one year, three years, five years and 10 years. These specific times were inherited by the time periods suggested by the authors mentioned previously. It is not necessary to carry out more frequent measurements, because recovery is a complex multidimensional process in which the changes only can be comprehended over time.

Based on previous experiences on a global level and in Italy, we conclude that the problems with urban services, facilities and transport described above usually come from the lack of community involvement in the recovery plan and its implementation. In the case of L'Aquila the opportunity to improve the resilience and the local capacity, the capacity to cope and recover [50] was missed due to the overwhelming force strategy applied by the government to respond to the emergency [4]. Hein [37] considers, that in order to implement a successful reconstruction plan, this must not only involve citizen participation, but also consider the surroundings affected in a secondary way, as in the case of the reconstruction of Kobe after 1995. Nevertheless, European cities do not have many opportunities for physical change, due to stone-building culture and the desire to retain the past. However, the case of L'Aquila could offer an opportunity to demonstrate the importance of considering the recovery as a holistic process in space, with variables as spatial connectivity, in the physical dimension, but also connected to the social, economic, cultural and environmental aspects in a synergetic way. In the same way, L'Aquila is an example that recovery needs to be regarded as part of disaster risk management activities, in which prevention and attention play a central role, in order to develop policies such as a 
pre-impact recovery plans reducing the need for intervention once a disaster occurs.

\section{Acknowledgment}

The data required to formulate this paper were collected in the MICRODIS project funded by the European Commission's Sixth Framework Programme. We gratefully acknowledge Professor Dr. David Alexander, for his valuable contributions to this paper and his support for the entire research; we would like also to thank Professor Ian Davis for his guidelines related to shelter and housing after disasters, and the editor Professor Dr. Murray Turoff, for his advice and encouragement. We extend our most sincere thanks to Bernadette Dubus, Roberto Miniati and Diego Guidotti for providing us with access to the data and metadata, and Alessandro Cacchione and the other members of the team of the Service for Spatial Information and Telematics, and the office of Geographic Information System of Abruzzo (Italy). We also thank Srirama Bhamidipati for the literature references suggested; Guido Baroncini Turrichia and Florian Albrecht for his support regarding local knowledge and data management and his, and Helena Merschdorf for her support for spell checking.

\section{References}

[1] E.L. Quarantelli, P. Lagadec, A. Boin, A heuristic approach to future disasters and crises: new, old, and in-between types, in: H. Rodríguez, E.L. Quarantelli, R.R. Dynes (Eds.), Handbook of Disaster Research, Springer, New York, 2007, pp. 14-41.

[2] D. Alexander, The L'Aquila earthquake of 6 April 2009 and Italian government policy on disaster response, J. Nat. Resour. Policy Res. 2 (2010) 325-342.

[3] UNIFI, Integrated health, social and economic impacts of extreme events: evidence, methods and tools, in: Annex 2 - Proposal Part B, 2009, p. 19

[4] D. Alexander, An Evaluation of the Recovery Strategy after 6 April 2009 Earthquake in L'Aquila, Central Italy, Disaster Planning and Emergency Management, 2010.

[5] I. Davis, Arquitectura de Emergencia, Gustavo Gili, Barcelona, 1980.

[6] E. Clausen, in: D. Standard.at (Ed.), L'Aquila drei Jahre nach Beben immer noch Geisterstadt, Panorama > Welt-Chronik, 2012.

[7] D. Alexander, An evaluation of medium-term recovery processes after the 6 April 2009 earthquake in L'Aquila, central Italy, Environ. Hazards (2012) 13.

[8] S. Wanczura, M. Angignard, L. Carreño, Glossary of definitions and relevant terms, in: MOVE (Ed.), Identification of Gaps in Existing Methods and Conceptualisation, 2011, p. 12.

[9] B. Wisner, Assessment of capability and vulnerability, in: G. Bankoff, G. Frerks, D. Hilhorst (Eds.), Mapping Vulnerability, Earthscan, London, 2004, pp. 183-193.

[10] K.J. Tierney, Businesses and disasters: vulnerability, impacts, and recovery, in: H. Rodríguez, E.L. Quarantelli, R.R. Dynes (Eds.), Handbook of Disaster Research, Springer, New York, 2007, pp. 275-296.

[11] S.E. Chang, Urban disaster recovery: a measurement framework and its application to the 1995 Kobe earthquake, Disasters 34 (2009) 303-327.

[12] L.J. Vale, T.J. Campanella, The cities rise again, in: L.J. Vale, T.J. Campanella (Eds.), The Resilient City: How Modern Cities Recover from Disaster, Oxford University Press, New York, 2005, pp. 3-23.

[13] D.E. Davis, Reverberations. Mexico city's 1985 earthquake and the transformation of the capital, in: L.J. Vale, T.J. Campanella (Eds.), The Resilient City: How Modern Cities Recover from Disaster, Oxford University Press, New York, 2005, pp. 255-280.

[14] B. Shohei, The evaluation of the status of disaster areas by using recovery indicators (in the case of the Great Hanshin-Awaji Earthquake), in: The 2nd . International Conference on Urban Disaster Reduction, Taipei, Taiwan, 2007.

[15] OECD, Handbook on Constructing Composite Indicators: Methodology and User Guide, OECD Publishing, 2008. , (2008).

[16] E. Dopheide, J. Martinez, Indicators, in: Planning and Management Tools, Special Lecture Notes Series, ITC, International Institute for geo-information science and earth observation - ITC, Enschede, The Netherlands, 2007, p. 29.
[17] V. Meentemeyer, Geographical perspectives of space, time, and scale, Landsc. Ecol. 3 (1989) 163-173.

[18] S.L. Cutter, GI science, disasters, and emergency management, Trans. GIS 7 (2003) 439-446.

[19] Y. Karatani, H. Hayashi, Quantitative evaluation of recovery process in disaster-stricken areas using statistical data, J. Disaster Res. 2 (2007) 453-464.

[20] Y. Karatani, H. Hayashi, Verification of recovery process under the great Hanshin-Awaji earthquake disaster based on the recovery index, in: 13th World Conference on Earhquake Engineering Vancouver, B.C., Canada, 2004, p. 14.

[21] FOPAE, Diagnostico de la Vulnerabilidad funcional urbana ante un evento desastroso en Santafe de Bogota, in: Alcadía Mayor de Bogota D.C., 1999, p. 241.

[22] L. Ozdamar, E. Ekinci, B. Kucukyazici, Emergency logistics planning in natural disasters, Ann. Oper. Res. 129 (2004) 217-245.

[23] Y.-C. Chiu, H. Zheng, Real-time mobilization decisions for multi-priority emergency response resources and evacuation groups: model formulation and solution, Transp. Res. Part E: Logist. Transp. Rev. 43 (2007) 710-736.

[24] F. Fiedrich, F. Gehbauer, U. Rickers, Optimized resource allocation for emergency response after earthquake disasters, Saf. Sci. 35 (2000) 41-57.

[25] S. Yan, Y.-L. Shih, A time-space network model for work team scheduling after a major disaster, J. Chin. Inst. Eng. 30 (2007) 63-75.

[26] S. Lang, P. Zeil, S. Kienberger, D. Tiede, Geons - policy-relevant geo-objects for monitoring high-level indicators, in: A. Car, G. Griesebner, J. Strobl (Eds.), GI Forum 2008, Centre for Geoinformatics Z_GIS, Salzburg, 2008, pp. 180-185.

[27] N. Limtanakool, M. Dijst, T. Schwanen, The influence of socioeconomic characteristics, land use and travel time considerations on mode choice for medium- and longer-distance trips, J. Transp. Geogr. 14 (2006) 327-341.

[28] M. Pacione, Urban Geography: A Global Perspective, Second edition Routledge, London, 2005. , (etc.).

[29] K. Sterrett, M. Hackett, D. Hill, The social consequences of broken urban structures: a case study of Belfast, J. Transp. Geogr. 21 (2012) 49-61.

[30] K. Lynch, The image of the city Ullstein, 1965. (Berlin).

[31] W.G. Peacok, N. Dash, Y. Zhang, Sheltering and housing recovery following disaster, in: H. Rodríguez, E.L. Quarantelli, R.R. Dynes (Eds.), Handbook of Disaster Research, Springer, New York, 2007, pp. 258-274.

[32] A.E. Bronner, Decision styles in transport mode choice, J. Econ. Psychol. 2 (1982) 81-101.

[33] D. Contreras, T. Blaschke, S. Kienberger, P. Zeil, Spatial vulnerability indicators: measuring recovery processes after earthquakes, in: M.A.S. Santos, Eliane Luísa Portela (Eds.), 8th International Conference on Information Systems for Crisis Response and Management, ISCRAM, Lisbon - Portugal, 2011.

[34] UNIFI, in: MICRODIS - Key Findings, UNIFI, 2011, p. 6.

[35] A. Field, Discovering Statistics using SPSS, Sage publications, Chenai, 2005.

[36] G.P. Smith, D. Wenger, Sustainable disaster recovery: operationalizing an existing agenda, in: H. Rodríguez, E.L. Quarantelli, R.R. Dynes (Eds.), Handbook of Disaster Research, Springer, New York, 2007, pp. 234-257.

[37] C. Hein, Resilient Tokyo: disaster and transformation in the Japanese city, in: L.J. Vale, T.J. Campanella (Eds.), The Resilient City: How Modern Cities Recover from Disaster, Oxford University Press, 2005, pp. 213-234.

[38] Birkmann Jörn, Fernando Nishara, Measuring revealed and emergent vulnerabilities of coastal communities to tsunami in Sri Lanka, Disasters 32 (2008) 82-105.

[39] D. Alexander, The L'Aquila earthquake of 6 April 2009 and Italian goverment policy on disaster response, Nat. Resour. Policy Res. (2010), (00).

[40] D. Alexander, Disasters, government and governance, Disaster Planning and Emergency Management, 2011.

[41] J.-Y. Wu, M. Lindell, Housing reconstruction after two major earthquakes: the 1994 Northridge earthquake in the United States and the 1999 Chi-Chi earthquake in Taiwan, Disasters 1 (2004) 36

[42] FOPAE, PNUD, Para despues del sismo, Bogota tiene un plan de vida, in: D.d.P.y.A.d. Emergencias (Ed.), 2009, p. 39.

[43] UNDP, in: UNDP Policy on Early Recovery, United Nations Development Programme, 2008, p. 35.

[44] D. Alexander, "From rubble to monument" revisited: modernised perspectives on recovery from disaster, in: D. Alexander, D.C. Henry, F. Andrew, J. Cassidy, L. Gonzalo (Eds.), Post-disaster Reconstruction Meeting Stakeholder Interests, Firenze University Press, Florence, Italy, 2006, p. 14.

[45] S.J. Hogg, Reconstruction following seismic disaster in Venzone, Friuli, Disasters 4 (1980) 173-185.

[46] L.J. Vale, T.J. Campanella, Conclusion. Axioms of resilience, in: L.J. Vale, T.J. Campanella (Eds.), The Resilient City: How Modern Cities Recover from Disaster, Oxford University Press, 2005, pp. 335-355.

[47] H. Yuichi, Implementation of the Kobe City recovery plan, Jpn. Soc. Innov. J. 1 (2011) 1-11. 
[48] C. Johnson, Strategic planning for post-disaster temporary housing, Disasters 31 (2007) 435-458.

[49] E. Clausen, L'Aquila drei Jahre Beben immer noch Geisterstadt, in: der Standard.at, der Standard, 2012.

[50] MOVE, B.t.n.f.a.t. guidelines, in: New Generic Framework Addressing Vulnerability and Disaster Risk to Natural Hazards from a Holistic Point of View, MOVE EUROPEAN COMMISSION DG ENVIRONMENT, 2010, p. 24.

MSc. Diana M. Contreras M. PhD student at the University of Salzburg, as well as a researcher at the Centre for Geoinformatics Z_GIS, in Austria between 2009 and 2012 and member of the UNIGIS staff since the present year. She holds a MSc degree in geo-information science and earth observation in the domain of urban planning and management from the International Institute for Geo-information Science and Earth Observation (ITC) in the Netherlands (2007). She carried out her postgraduate degree studies in the field of risk evaluation and disaster prevention at the Andes University in Colombia (2002). Her bachelor's degree is in the field of architecture, gained from the National University of Colombia (2001). She has worked at the District Office of Emergency Prevention and Management (DPAE), in Bogotá D.C and with private consultants in projects related with risk management in Colombia (2001-2007). Her work as practitioner and academic has been recognized and honored several times, not only in Colombia but also in the USA (2001-2010).

Prof. Dr. Thomas Blaschke. Professor for Geoinformatics at the University of Salzburg, co-director of the Centre for Geoinformatics, as well as head of both the Research Studio iSPACE, and Research Studio Austria FG. His research interests include methodological issues of the integration of GIS, remote sensing and image processing. He also focuses on disaster management, particularly challenges such integration of methods and domain knowledge into spatial analysis and GIS-based spatial decision support systems. Prior positions include several lecturer, senior lecturer and professor positions in Germany, Austria and the UK, as well as temporary affiliations as guest professor, and visiting scientist. He is author, co-author or editor of $>270$ scientific publications including 17 books, and received several academic prices and awards including the Christian-Doppler Prize 1995.
Dr. Stefan Kienberger. Researcher at the Centre for Geoinformatics at the University of Salzburg and obtained his MSc in Environmental System Sciences/Geography from the University of Graz and Macquarie University Sydney, Australia. His PhD research at Z_GIS focused on the spatial assessment of vulnerability, integrating community-based approaches and GIS/Remote Sensing methodologies at the community and district level in Mozambique. His research activities include the modelling of integrated indicators and spatial analysis. He has been involved in several international research and capacity building projects and gained specific expertise on vulnerability assessment in Austria, Africa and Asia.

Dipl. Peter Zeil. Senior Project Manager at the Centre for Geoinformatics Z_GIS, and visiting professor of the Department for Geography and Applied Geoinformatics at the University of Salzburg. He obtained his bachelor's degree in Geophysics from the University of München, Germany. He has been involved in several international research and capacity building projects related to applied remote sensing for vegetation resources management and disaster management in Latin America, Austria, Africa and Asia. 